\title{
Article \\ Comparative RNA-Seq Analysis Reveals Potentially Resistance-Related Genes in Response to Bacterial Canker of Tomato
}

\author{
Leonardo I. Pereyra-Bistraín ${ }^{1,+}+\mathbb{D}$, Cesaré Ovando-Vázquez ${ }^{2,+}\left(\mathbb{D}\right.$, Alejandra Rougon-Cardoso ${ }^{3, *(\mathbb{D})}$ \\ and Ángel G. Alpuche-Solís 1,*(D)
}

check for updates

Citation: Pereyra-Bistraín, L.I.; Ovando-Vázquez, C.;

Rougon-Cardoso, A.; Alpuche-Solís, Á.G. Comparative RNA-Seq Analysis Reveals Potentially ResistanceRelated Genes in Response to Bacterial Canker of Tomato. Genes 2021, 12, 1745. https://doi.org/ 10.3390/genes12111745

Academic Editor:

Abdelhafid Bendahmane

Received: 2 October 2021

Accepted: 26 October 2021

Published: 29 October 2021

Publisher's Note: MDPI stays neutral with regard to jurisdictional claims in published maps and institutional affiliations.

Copyright: (c) 2021 by the authors. Licensee MDPI, Basel, Switzerland. This article is an open access article distributed under the terms and conditions of the Creative Commons Attribution (CC BY) license (https:/ / creativecommons.org/licenses/by/ $4.0 /)$.
1 División de Biología Molecular, Instituto Potosino de Investigación Científica y Tecnológica A.C., San Luis Potosí 78216, Mexico; leonardo.pereyra@ipicyt.edu.mx

2 Centro Nacional de Supercómputo, Instituto Potosino de Investigación Científica y Tecnológica A.C., Consejo Nacional de Ciencia y Tecnología, San Luis Potosí 78216, Mexico; cesare.ovando@ipicyt.edu.mx

3 Laboratory of Agrigenomic Sciences, Universidad Nacional Autónoma de México, ENES-León, León 37689, Mexico

* Correspondence: arougon@enes.unam.mx (A.R.-C.); alpuche@ipicyt.edu.mx (Á.G.A.-S.); Tel.: +52-(444)-834-2000 (Á.G.A.-S.)

$+\quad$ These authors contributed equally to this work.

Abstract: Tomato is one of the most important crops for human consumption. Its production is affected by the actinomycete Clavibacter michiganensis subsp. michiganensis ( $\mathrm{Cmm}$ ), one of the most devastating bacterial pathogens of this crop. Several wild tomato species represent a source of natural resistance to $\mathrm{Cmm}$. Here, we contrasted the transcriptomes of the resistant wild tomato species Solanum arcanum LA2157 and the susceptible species Solanum lycopersicum cv. Ailsa Craig, during the first $24 \mathrm{~h}$ of challenge with $\mathrm{Cmm}$. We used three analyses approaches which demonstrated to be complementary: mapping to S. lycopersicum reference genome SL3.0; semi de novo transcriptome assembly; and de novo transcriptome assembly. In a global context, transcriptional changes seem to be similar between both species, although there are some specific genes only upregulated in S. arcanum during $\mathrm{Cmm}$ interaction, suggesting that the resistance regulatory mechanism probably diverged during the domestication process. Although S. lycopersicum showed enriched functional groups related to defense, $S$. arcanum displayed a higher number of induced genes related to bacterial, oomycete, and fungal defense at the first few hours of interaction. This study revealed genes that may contribute to the resistance phenotype in the wild tomato species, such as those that encode for a polyphenol oxidase E, diacyl glycerol kinase, TOM1-like protein 6, and an ankyrin repeat-containing protein, among others. This work will contribute to a better understanding of the defense mechanism against $\mathrm{Cmm}$, and the development of new control methods.

Keywords: arcanum; bacterial canker; Clavibacter; gene expression; RNA-Seq; tomato; transcriptome

\section{Introduction}

Tomato is one of the most important crops for human consumption. Its production can be affected by several phytopathogens. The actinomycete Clavibacter michiganensis subsp. michiganensis $(\mathrm{Cmm})$ is the causal agent of the bacterial canker of tomato. This disease was described more than 100 years ago in Michigan, United States [1], and now it is present in almost all tomato-producing areas [2]. C $\mathrm{mm}$ is considered one of the most devastating pathogens of this crop [3]. If disease spreading is not properly controlled, the tomato production can be severely affected in fields and protected agriculture. In Mexico, about 200 hectares of greenhouse crops were lost in 2006, reaching a 40 million dollars loss [4].

$\mathrm{Cmm}$ can infect tomato plants through wounds and natural entries such as stomata, hydathodes, and trichomes [5,6]. The typical transmission sources are infected tomato 
seeds, infected young seedlings, and residual plants in the soil [7-9]. Symptoms such as the unilateral wilting of leaves, cankers on stems, and the development of bird-eye spots in infected fruits are characteristic of the tomato bacterial canker [10]. Moreover, this pathogenic bacterium can survive in soil and plant debris for more than two years [11,12], which represents an infection source for subsequent farming seasons.

To date, there are no effective containment approaches against $\mathrm{Cmm}$, and most of them are cultural practices and chemical control methods. Generally, several copper salts and antimicrobial compounds are used for chemical control, however, they can induce pathogen resistance, phytotoxicity, and phreatic surface pollution $[13,14]$.

Several wild tomato species have been described as tolerant to $\mathrm{Cmm}$ infection, including Solanum arcanum, Solanum habrochaites, and Solanum pimpinellifolium. In these species, several quantitative trait loci have been associated with the defense response against this pathogenic bacterium [15-17]. S. arcanum LA2157 has been characterized with the highest degree of resistance against $\mathrm{Cmm}[15,18]$. These wild tomato species can be considered a natural source of resistance that could be used for the improvement of the commercial tomato species $S$. lycopersicum by incorporation of resistance-related genes.

Previous studies have used differential gene expression analysis to identify genes probably associated with disease symptoms development during the S. lycopersicum-Cmm interaction. In one study, where microarrays were used, genes related to host-derived ethylene production were detected [19]. In another work, cDNA-AFLP was used to investigate the interaction of $\mathrm{Cmm}$ with two resistant wild tomato species and the susceptible tomato species $S$. lycopersicum. As a result, several differentially expressed genes, putatively associated with the tomato resistance, were identified [20]. Nevertheless, both methods may not represent the complete set of transcribed genes, due to technical limitations. RNA-Seq is a next generation sequencing technology that has been widely used in the last ten years. It allows one to obtain almost complete gene expression profiles in a specific condition, overcoming the limitations of other transcriptomic analysis tools, such as microarrays. Furthermore, RNA-Seq downstream analyses permit the classification and quantification of the whole diversity of RNA sequences, either by using an annotated genomic reference, or by de novo assembling the obtained sequences. This de novo strategy also allows for the detection of new genes and alternative splicing events [21-23].

In this study, we aimed to identify genes potentially related to the defense response against $\mathrm{Cmm}$ during the first hours of interaction, using RNA-Seq. For that purpose, we contrasted the global transcriptional changes of the non-model resistant wild tomato species S. arcanum LA2157 and the susceptible species S. lycopersicum cv. Ailsa Craig during the first $24 \mathrm{~h}$ of interaction with $\mathrm{Cmm}$. This was performed using three different approaches of data analyses: mapping the RNA-Seq fragments to S. lycopersicum reference genome SL3.0 (MR); performing a semi de novo transcriptome assembly (STA); and a de novo transcriptome assembly (DA). Here, we report a multi-bioinformatics approach to compare the transcriptomes of two tomato species during the $\mathrm{Cmm}$ infection. Data provided in this study contribute to the screening of defense response genes on Solanum species.

\section{Results}

\subsection{Infection of Tomato Plants with Cmm 1569}

To obtain the genetic material for the analysis of S. lycopersicum and S. arcanum LA2157 during the interaction with Cmm 1569, we collected leaves of infected plants at 0,8 , and $24 \mathrm{~h}$ post-inoculation (hpi). We followed the disease development symptoms in both tomato species. S. lycopersicum infected plants developed the characteristic disease symptoms at 25 days post-inoculation (dpi). The symptoms were the unilateral wilting of leaves, and the stem canker extending far from the inoculation site, whereas mock-inoculated S. lycopersicum control plants had normal stems and leaves (Figure 1a-d). In the resistant species S. arcanum LA2157, the infected plants did not show these typical disease symptoms. Instead, the inoculated plants only showed a small canker wound located in the inoculation site of each plant that did not spread through the stem, therefore, the phenotype of the 
S. arcanum LA2157 infected plants was very similar to the control plants (Figure 1e-h). In summary, both tomato species displayed the expected phenotype after $\mathrm{Cmm}$ inoculation.

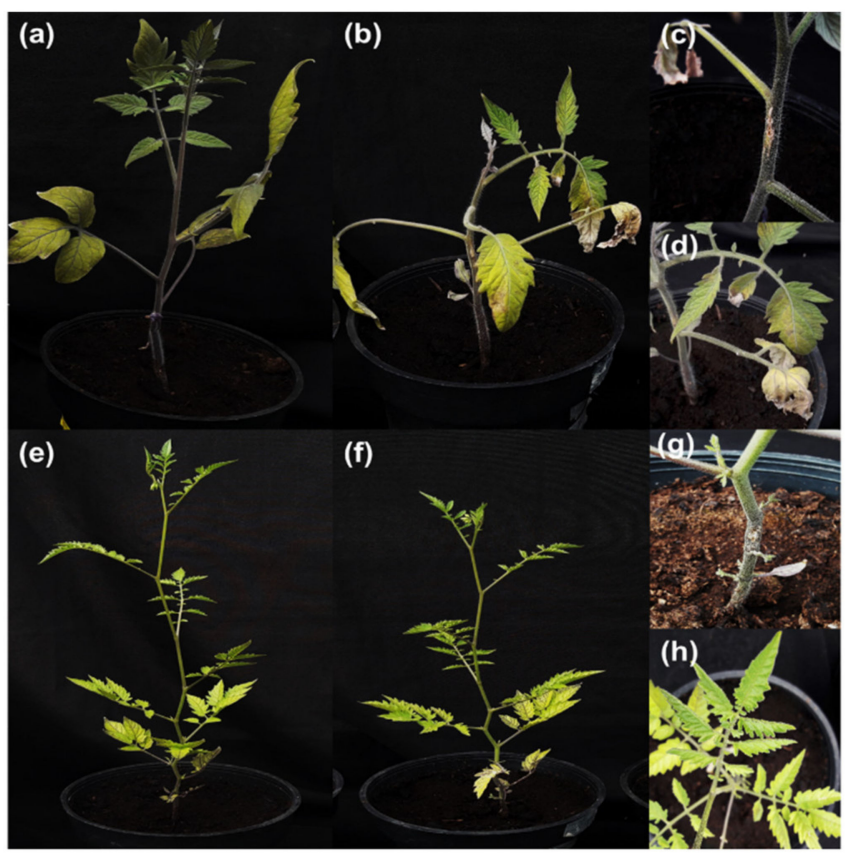

Figure 1. Development of disease symptoms in S. lycopersicum cv. Ailsa Craig and S. arcanum LA2157 infected with the Cmm 1569 strain. (a) S. lycopersicum plant 25 days after mock-inoculation. (b) S. lycopersicum $25 \mathrm{dpi}$, the plant showed the characteristic disease symptoms of bacterial canker. (c,d) S. lycopersicum $25 \mathrm{dpi}$, leaves showing unilateral wilt, and stem showing canker development. (e) S. arcanum plant 25 days after mock-inoculation. (f) S. arcanum 25 dpi. (g,h) S. arcanum 25 dpi, leaves and stem without disease symptoms.

\subsection{Mappings Stats and Transcript Quantification}

We sequenced 18 libraries, resulting in fastq files ranging from 32-58 million reads of $150 \mathrm{bp}$ each. We decided to analyze the sequencing data using three different strategies, which we will refer to as MR, STA, and DA (Figure 2; see Section 5). Simultaneously, these strategies allowed us to develop a comparative analysis among the three strategies, and obtain a consensus result suitable for detecting genes potentially related to a defense response against $\mathrm{Cmm}$.

For the MR strategy, the percentage of mapped reads varied depending on the library, but on average, $77.3 \%$ of S. arcanum LA2157 and $92.4 \%$ of S. lycopersicum reads mapped to the reference genome (mapped to exonic, intronic, intergenic, and unassigned regions), resulting in a small percentage of unmapped reads to the reference (Figure 3a). In order to determine the sample similarity, we performed a principal component analysis (PCA). The biological replicates were grouped among them on each studied condition (i.e., 0, 8, and $24 \mathrm{hpi}$; Figure 3b). In the STA strategy, the average percentage of mapped reads for the $S$. arcanum species was $75.4 \%$, and $78.6 \%$ for S. lycopersicum (Figure 3c). The mapping percentage of the S. arcanum libraries slightly decreased with this strategy, and noticeably diminished for the S. lycopersicum ones. This last decrease could have occurred because we only considered the coding regions from the reference genome and the de novo-assembled transcripts from unmapped reads for the STA strategy. The PCA obtained with this strategy presented the same distribution patterns for each group of biological replicates compared to the MR strategy (Figure 3d). With the DA pipeline, the average mapping percentage was $83.6 \%$ for S. arcanum LA2157 libraries, and $86.2 \%$ for S. lycopersicum libraries (Figure 3e). The grouping patterns in the PCA with the DA strategy agreed with the other two strategies (Figure $3 \mathrm{f}$ ). Therefore, the application of either mapping approach did 
not affect the sample similarity of biological replicates. In parallel, we took advantage of the performed analyses to evaluate the computing time required for each strategy. For the de novo transcriptome, the assembly took $\sim 279 \mathrm{~h}$ compared to $\sim 25 \mathrm{~h}$ for the semi de novo transcriptome assembly and $\sim 3 \mathrm{~h}$ for the mapping to the reference genome strategy (Table S1), pointing to considerable differences in the computing time required for each approach.

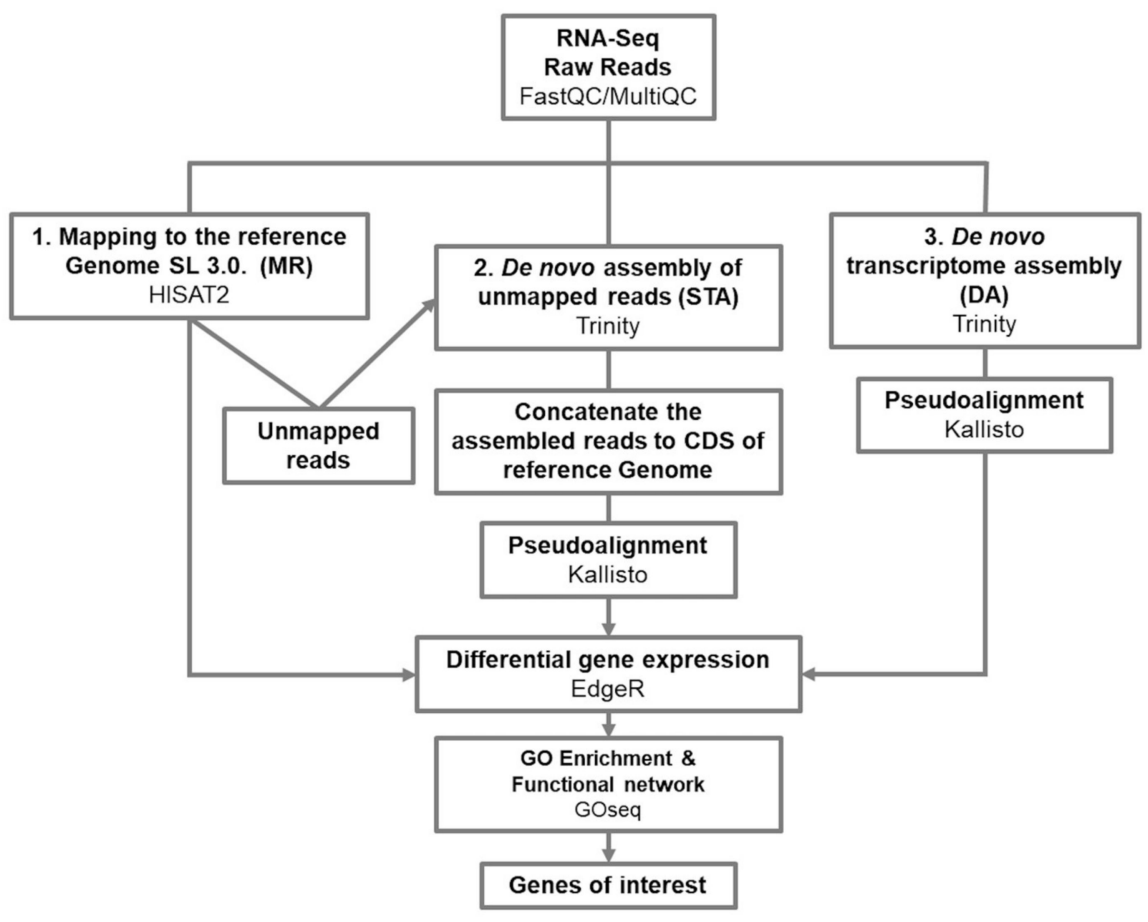

Figure 2. RNA-Seq data processing pipelines. The scheme summarizes the three strategies for data analysis: direct mapping to the reference genome of Solanum lycopersicum SL3.0, MR; (left), de novo assembly of unmapped reads, STA; (center), and de novo transcriptome assembly, DA (right). Processes and strategies are shown in bold and bioinformatic packages used for those processes are represented in light font.

\subsection{Differentially Expressed Genes in Response to Cmm 1569}

We determined the number of differentially expressed genes (DEGs) in each strategy of analysis. The statistical significance was evaluated by establishing a false discovery rate (FDR) limit of 0.01 for data mapped to the reference genome SL3.0, and an FDR value of 0.1 for data mapped to the semi de novo and the de novo-assembled transcriptomes. The 0.1 FDR value was established considering that the reads mapped to 77,515 and 49,340 transcripts for the STA and DA approaches, respectively (Table S2), even though there are about 35,000 genes annotated in the tomato genome (one transcript per gene). Therefore, the reads could be assigned to several transcript isoforms coming from the same gene, and a restrictive FDR cutoff could result in the assignment of less DEGs. Table 1 provides the number of DEGs detected in each analysis. By setting up these FDR thresholds, we obtained comparable numbers of differential transcripts in all three strategies.

The entire dispersion patterns of DEGs are shown in Figure S1. The average percentage of up-regulated genes from 0 to $8 \mathrm{hpi}$ in the three approaches was similar in S. lycopersicum and S. arcanum ( $7.46 \%$ compared to $6.57 \%$, respectively), whereas the average percentage of down-regulated genes in S. lycopersicum was higher compared to S. arcanum species at this same time (9.28\% compared to $6.08 \%$, respectively). Regarding the 8 to $24 \mathrm{hpi}$ transition time, the average percentage of induced and repressed genes was higher in S. arcanum compared to S. lycopersicum (Table 1). 

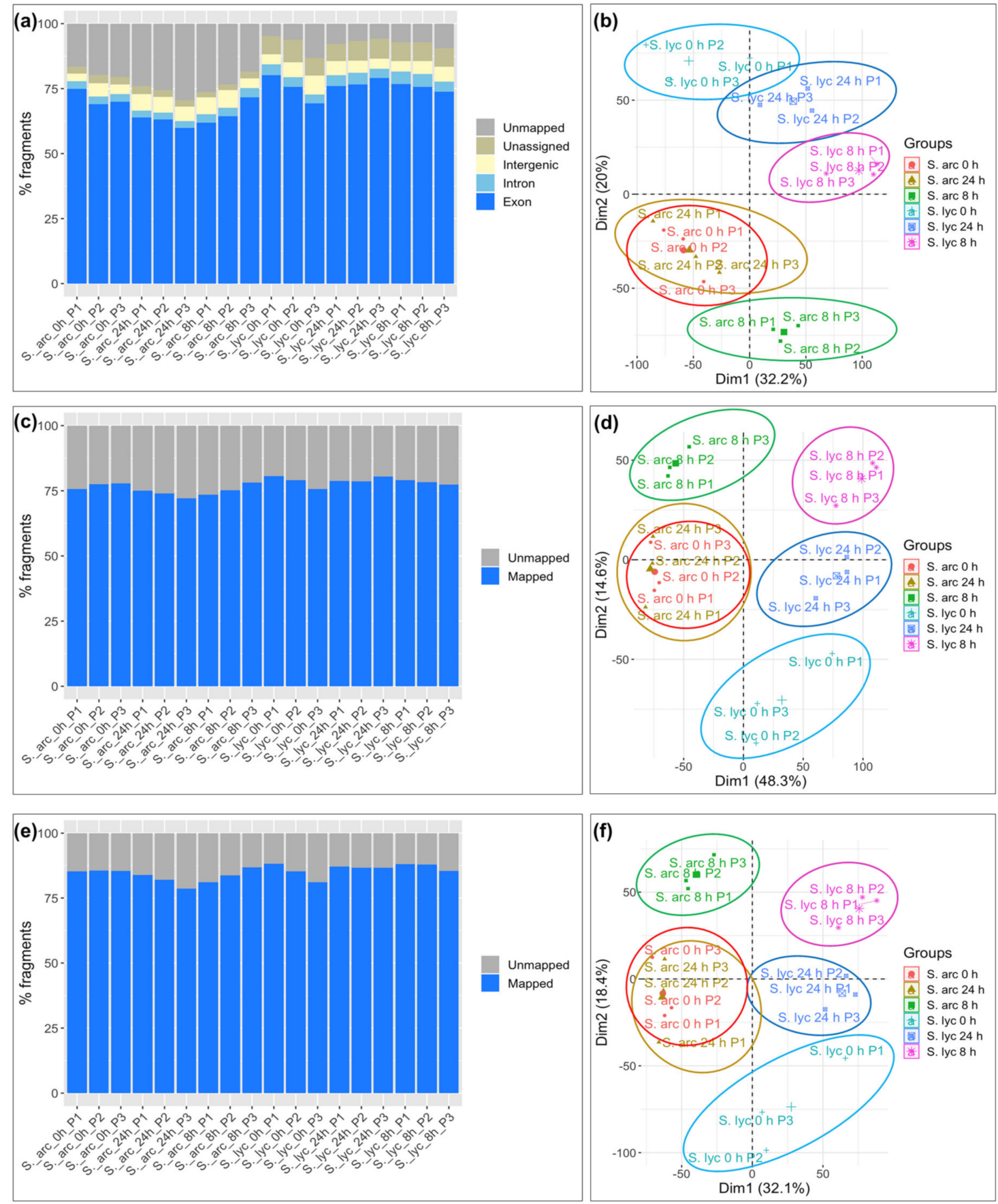

Figure 3. Mapping statistics of S. arcanum LA2157 and S. lycopersicum cDNA libraries, and sample similarity determined by principal component analysis (PCA). (a,b) Reads mapped to the S. lycopersicum SL3.0 reference genome (MR) and PCA. The average percentage of mapped reads was $77.3 \%$ for S. arcanum, and $92.4 \%$ for S. lycopersicum. (c,d) Mapping of sequence reads to the de novo-assembled unmapped reads, plus exonic regions of reference genome SL3.0 (STA) and PCA. The average percentage of mapped reads was $75.4 \%$ for S. arcanum, and $78.6 \%$ for S. lycopersicum. (e,f) Mapping of sequence reads to the de novo transcriptome assembly (DA) and PCA. The average percentage of mapped reads was $83.3 \%$ for S. arcanum, and $86.2 \%$ for S. lycopersicum. PCAs showed that biological replicates grouped correctly by study time $(0,8$, and $24 \mathrm{hpi}$, accordingly) in all approaches. Count matrix adjusted by Z-score. 
Table 1. Differentially expressed genes identified in each strategy.

\begin{tabular}{|c|c|c|c|c|c|}
\hline \multirow{2}{*}{$\begin{array}{c}\text { Plant Species } \\
\text { Reference Genome SL3.0 }\end{array}$} & \multicolumn{2}{|c|}{ 0-8 hpi } & \multicolumn{2}{|c|}{ 8-24 hpi } & \multirow{2}{*}{$\frac{\text { Genes/Transcripts }}{\text { Total }}$} \\
\hline & Up & Down & Up & Down & \\
\hline S. lycopersicum & 1421 & 1483 & 295 & 245 & 14,477 \\
\hline S. arcanum LA2157 & 1100 & 997 & 884 & 679 & FDR 0.01 \\
\hline \multicolumn{6}{|l|}{ Semi de novo assembly } \\
\hline S. lycopersicum & 1602 & 2249 & 500 & 277 & 24,741 \\
\hline S. arcanum LA2157 & 1687 & 1481 & 1315 & 1356 & FDR: 0.1 \\
\hline \multicolumn{6}{|l|}{ De novo assembly } \\
\hline S. lycopersicum & 1409 & 1968 & 419 & 247 & 23,112 \\
\hline S. arcanum LA2157 & 1229 & 1244 & 1152 & 908 & FDR: 0.1 \\
\hline \multicolumn{6}{|l|}{ Average percentage of DEGs } \\
\hline S. lycopersicum & 7.46 & 9.28 & 1.95 & 1.29 & \\
\hline S. arcanum LA2157 & 6.57 & 6.08 & 5.46 & 4.69 & \\
\hline$p$-value & 1.0 & 0.1 & 0.1 & 0.1 & \\
\hline
\end{tabular}

Up: induced genes. Down: repressed genes. FDR: false discovery rate.

Differences in induced and repressed genes in S. arcanum and S. lycopersicum could be seen as a starting point to search for genes involved in a defense response to $\mathrm{Cmm}$. We detected shared genes between S. lycopersicum and S. arcanum LA2157 considering the DEGs and transition times (Figure 4). Regarding induced genes in S. arcanum and repressed in S. lycopersicum, 28 to 54 genes were detected from 0 to $8 \mathrm{hpi}$, indicating a similar number of genes in all strategies of analysis (Figure 4a). However, from the 8 to $24 \mathrm{hpi}$ for shared induced genes in S. arcanum and repressed in S. lycopersicum, only one gene was detected by the DA strategy, and four genes by the STA one (Figure 4b). Depending on the strategy, 528 to 976 induced genes were detected exclusively in S. arcanum from 0 to 8 hpi (Figure 4a). At the same time, a similar number of induced genes was detected in S. lycopersicum only (around 900 genes in each analysis). Relative to the 8 to 24 hpi transition, between 689 and 1081 genes were induced in S. arcanum solely, and only from 100 to 267 in S. lycopersicum (Figure $4 \mathrm{~b}$ ). Regarding induced genes shared in both tomato species from 0 to $8 \mathrm{hpi}$, we detected 476 to 657 genes per strategy (Figure 4a). As for 8 to $24 \mathrm{hpi}$, around 200 genes were detected in each approach (Figure $4 \mathrm{~b}$ ). A similar number of repressed genes shared in both species, and time transitions, are visualized in Figure 4. Importantly, a higher number of repressed genes was detected solely in S. lycopersicum compared with S. arcanum from 0 to 8 hpi (Figure 4a), and this behavior was the opposite from 8 to 24 hpi (Figure $4 \mathrm{~b}$ ), which suggests a downregulation provoked by Cmm in S. lycopersicum. Remarkably, the overall results presented the same tendencies regardless of the used strategy.

\subsection{Gene Ontology Term Enrichment Analysis in S. lycopersicum and S. arcanum LA2157}

In order to determine the global transcriptional context of both tomato species in response to $\mathrm{Cmm}$, we performed a gene ontology (GO) enrichment analysis considering the $\log$ fold change $(\log F C)$ values and $-\log 10$ FDR values of DEGs. After extracting the enriched groups of each approach, we selected enriched GO terms that could be directly associated with an infection response caused by $\mathrm{Cmm}$. In addition, enrichment scores of the selected functional groups of S. lycopersicum and S. arcanum were compared in order to detect which tomato species exhibited the higher enrichment. The complete enriched GO terms can be found in Figures S2-S4. 
(a)

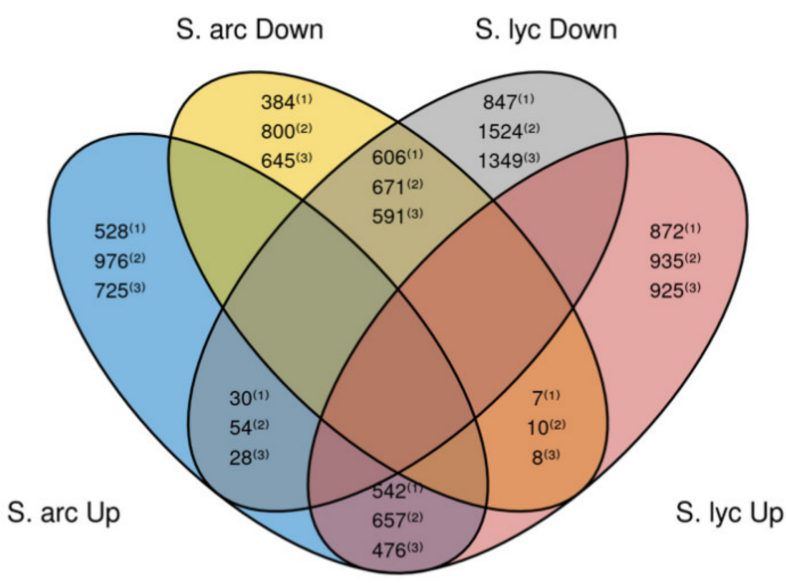

(b)

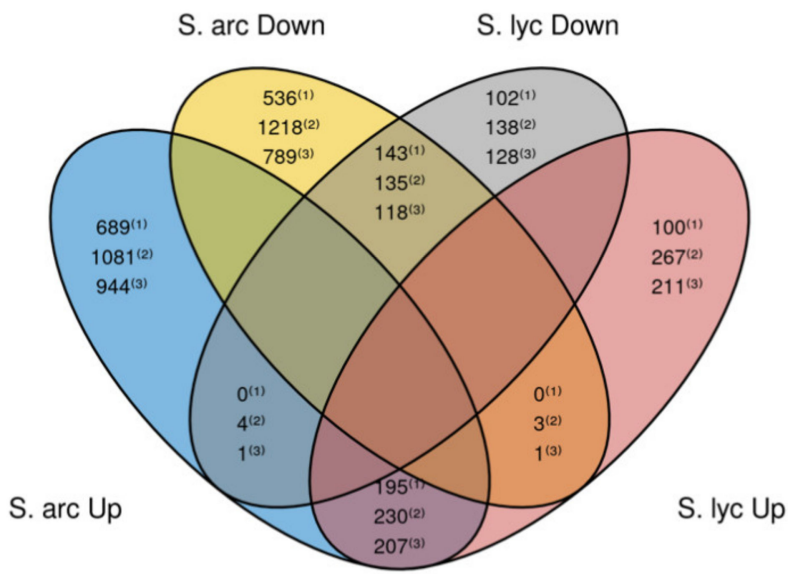

Figure 4. Venn diagrams showing DEGs contrasts between S. lycopersicum cv. Ailsa Craig and S. arcanum LA2157. (a) Contrasts of DEGs from 0 to 8 hpi transition. (b) Contrasts of DEGs from 8 to 24 hpi transition. (1) Mapping of reads to the reference genome SL3.0 (MR); FDR value 0.01. (2) Mapping to the semi de novo assembled transcriptome (STA); FDR value 0.1. (3) Mapping to the de novo assembled transcriptome (DA); FDR value 0.1.

Several functional groups were enriched in both S. lycopersicum and S. arcanum in the three strategies of analysis, including hydrolase activity (GO:0016787), proteasome complex (GO:0000502), and response to cytokinin (GO:0009735). However, they were enriched differently either by induced or repressed genes, depending on the tomato species and time of study (Figure 5a-c). Similarly, we detected functional groups only enriched in one of the three strategies of analysis, such as nuclear proteasome complex (GO:0031595) and threonine type endopeptidase activity (GO:0004298), which were enriched only when we mapped the reads to the de novo-assembled transcriptome (Figure $5 \mathrm{c}$ ). Thus, we observed that some functional groups were not enriched using the MR and STA strategies and could be only appreciated employing the DA approach.

Importantly, the more general functional group defense response (GO:0006952) was enriched in the three strategies of analysis. This functional group exhibited a higher enrichment by induced genes in S. lycopersicum from 0 to 8 hpi in all cases (Figure 5). However, the more specific functional groups corresponding with defense response to bacteria (GO:0042742), as well as with the defense response to fungus (GO:0050832), showed a stronger enrichment by induced genes in S. arcanum from 0 to $8 \mathrm{hpi}$. This behavior was consistent in all three analysis approaches (Figure 5).

\subsection{DEGs Presumably Associated with the Defense Response against Cmm 1569}

Using the results of all applied strategies, we aimed to obtain a list of genes potentially related to defense against $\mathrm{Cmm}$. To do this, we first detected relevant genes in each approach considering the LogFC values, the comparisons (shared and unshared genes between the two tomato species), the GO term enrichment analysis, and the gene functional annotation. Then, we compiled the genes in a single list (Table 2). Genes that appeared in more than one approach (same gene identifier) were arbitrarily reported in one method only, to avoid redundancies. The complete gene expression lists can be observed in Tables S3-S8. 


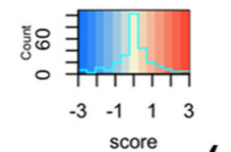

(a)

(b)

(c)

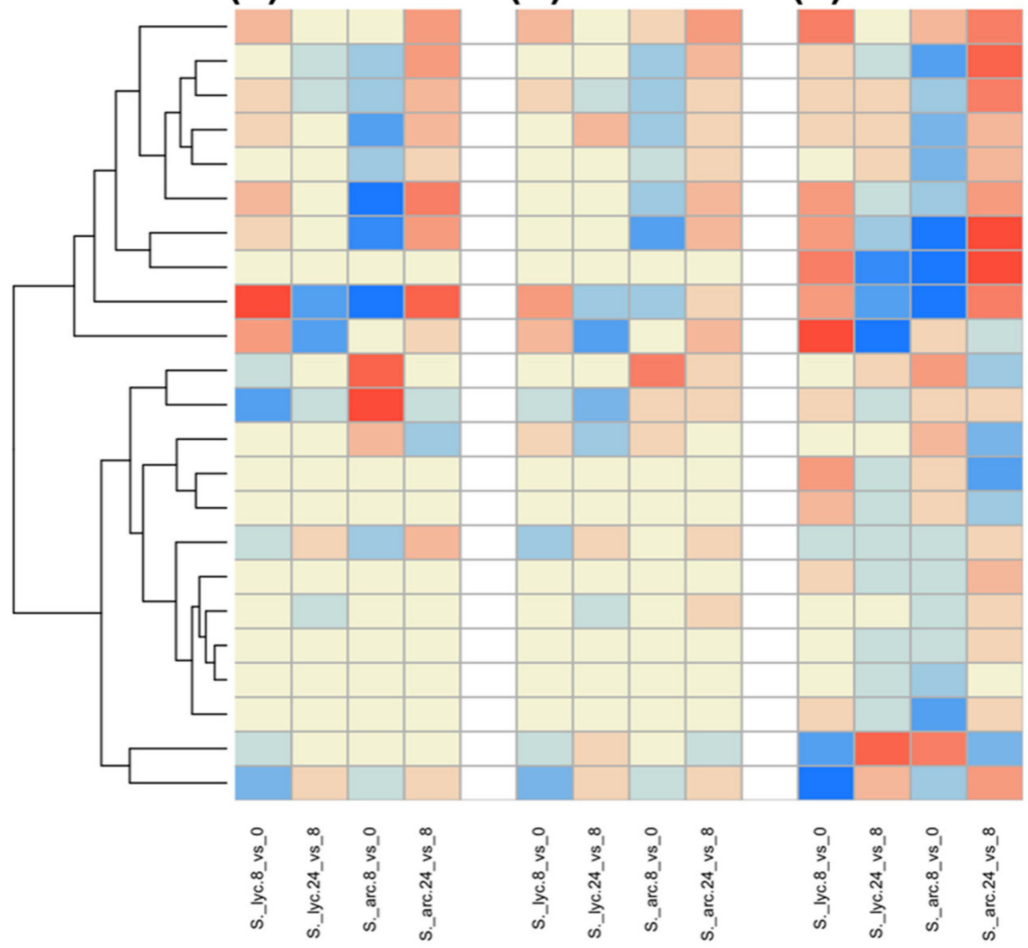

GO:0031408-oxylipin biosynthetic process

GO:0005681-spliceosomal complex

GO:0016787-hydrolase activity

GO:0071013-catalytic step 2 spliceosome

GO:0016567-protein ubiquitination

GO:0071011-precatalytic spliceosome

GO:0000398-mRNA splicing, via spliceosome

GO:0004298-threonine-type endopeptidase activity

GO:0000502-proteasome complex

GO:0006952-defense response

GO:0009611-response to wounding

GO:0050832-defense response to fungus

GO:0042742-defense response to bacterium

GO:0004675-transmembrane receptor protein serine/threonine kinase

GO:0009753-response to jasmonic acid

GO:0031625-ubiquitin protein ligase binding

GO:0004842-ubiquitin-protein transferase activity

GO:0006979-response to oxidative stress

GO:0004252-serine-type endopeptidase activity

GO:0031597-cytosolic proteasome complex

GO:0031595-nuclear proteasome complex

GO:0009737-response to abscisic acid

GO:0009735-response to cytokinin

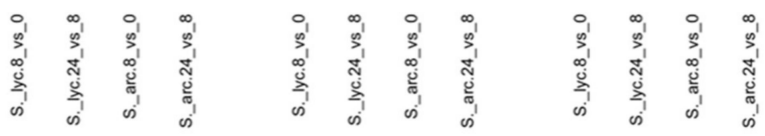

Figure 5. GO term enrichment analysis. Heatmaps representing the main enriched functional groups in each strategy of analysis, contrasting the enrichment level of each species. (a) Mapping to the reference genome SL3.0 (MR). (b) Mapping to the semi de novo-assembled transcriptome (STA). (c) Mapping to the novo-assembled transcriptome (DA). The score values were obtained using the $\log F C$ and the $-\log 10$ of FDR of DEGs.

Table 2. Selected DEGs potentially related to resistant response against $\mathrm{Cmm}$.

\begin{tabular}{|c|c|c|c|c|c|}
\hline Gene/Transcript ID & Description & $\begin{array}{l}\text { S. } \operatorname{arc} \operatorname{LogFC} \\
(0-8 \mathrm{hpi})\end{array}$ & $\begin{array}{l}\text { S. } \operatorname{lyc} \operatorname{LogFC} \\
\text { (0-8 hpi) }\end{array}$ & $\begin{array}{l}\text { S. } \operatorname{arc} \operatorname{LogFC} \\
(8-24 \mathrm{hpi})\end{array}$ & $\begin{array}{l}\text { S. lyc LogFC } \\
\text { (8-24 hpi) }\end{array}$ \\
\hline \multicolumn{6}{|c|}{ Reference genome } \\
\hline Solyc06g074030.1 & $\begin{array}{c}\text { CCR4-associated factor } 1 \\
\text { homolog } 9\end{array}$ & $3.14 *$ & $-3.85 *$ & -2.16 & -1.07 \\
\hline Solyc06g071280.3 & Protein EDS1B & $2.32 *$ & $-1.66^{*}$ & $-1.73 *$ & -0.46 \\
\hline Solyc02g081500.3 & Rust resistance kinase $\operatorname{Lr} 10$ & $2.62 *$ & $-1.87 *$ & $-1.80 *$ & -0.23 \\
\hline Solyc02g092140.1 & $\begin{array}{c}\text { Protein PHLOEM PROTEIN } \\
\text { 2-LIKE A10 }\end{array}$ & $5.37 *$ & $1.49 *$ & $-2.96 *$ & -1.47 \\
\hline Solyc08g074620.3 & Polyphenol oxidase E & $5.65 *$ & -0.38 & 0.07 & 3.03 \\
\hline Solyc05g051530.3 & $\mathrm{ABC}$ transporter $\mathrm{G}$ family member 11 & $5.48^{*}$ & -0.04 & $-4.90 *$ & -2.55 \\
\hline Solyc11g017270.2 & $\begin{array}{l}\text { Leucine-rich repeat receptor-like } \\
\text { serine/threonine-protein kinase }\end{array}$ & $1.60 *$ & $-1.20 *$ & -0.53 & 0.71 \\
\hline Solyc08g080830.3 & $\begin{array}{c}\text { Probable LRR receptor-like } \\
\text { serine/threonine-protein } \\
\text { kinase }\end{array}$ & $1.05^{*}$ & 0.48 & $-0.69 *$ & -0.23 \\
\hline Solyc12g009140.2 & Proteasome subunit $\alpha$ type-6-B & $-0.83 *$ & -0.31 & $0.84 *$ & 0.22 \\
\hline Solyc01g109590.3 & $\begin{array}{l}\text { Probable receptor-like } \\
\text { serine/threonine protein kinase }\end{array}$ & $2.65 *$ & $1.58 *$ & $-2.16^{*}$ & -1.09 \\
\hline \multicolumn{6}{|c|}{ Semi de novo assembly } \\
\hline TRINITY_DN15795_c0_g2_i2 & $\begin{array}{c}\text { Serine-type endopeptidase } \\
\text { inhibitor activity }\end{array}$ & $6.19 *$ & $-1.30 *$ & 0.97 & 0.04 \\
\hline Solyc08g062360.3 & Ankyrin repeat-containing protein & $2.14 *$ & $-2.67 *$ & $-2.70 *$ & -0.88 \\
\hline Solyc06g066370.3 & WRKY transcription factor WRKY24 & $1.33 *$ & $-1.38 *$ & -0.96 & 0.51 \\
\hline Solyc12g049330.2 & E3 ubiquitin-protein ligase SPL2 & $6.65 *$ & -0.05 & -1.15 & -0.06 \\
\hline Solyc05g012900.3 & $\begin{array}{l}\text { Putative late blight resistance protein } \\
\text { homolog R1B-23 }\end{array}$ & $5.36 *$ & -1.62 & -1.03 & 0.85 \\
\hline Solyc07g005090.3 & Class V chitinase & $2.84 *$ & $1.65^{*}$ & 0.83 & 0.07 \\
\hline Solyc06g083390.3 & RPM1-interacting protein 4 & $1.29 *$ & $-1.55 *$ & -0.74 & -0.31 \\
\hline Solyc10g008010.3 & Proteasome subunit $\alpha$ type- 2 & -0.67 & 0.10 & $1.02 *$ & -0.09 \\
\hline Solyc12g007110.2 & $\begin{array}{l}\text { Proline-rich receptor-like } \\
\text { protein kinase PERK1 }\end{array}$ & $1.36^{*}$ & 0.44 & $-0.81 *$ & 0.49 \\
\hline
\end{tabular}


Table 2. Cont.

\begin{tabular}{|c|c|c|c|c|c|}
\hline Gene/Transcript ID & Description & $\begin{array}{l}\text { S. } \operatorname{arc} \operatorname{LogFC} \\
(0-8 \mathrm{hpi})\end{array}$ & $\begin{array}{l}\text { S. } \operatorname{lyc} \operatorname{LogFC} \\
(0-8 \mathrm{hpi})\end{array}$ & $\begin{array}{l}\text { S. arc LogFC } \\
\text { (8-24 hpi) }\end{array}$ & $\begin{array}{l}\text { S. } \operatorname{lyc} \operatorname{LogFC} \\
(8-24 \text { hpi) }\end{array}$ \\
\hline \multicolumn{6}{|c|}{ De novo assembly } \\
\hline TRINITY_DN22346_c2_g3_i1 & $\begin{array}{l}\text { L-type lectin-domain } \\
\text { containing receptor kinase }\end{array}$ & $2.44 *$ & $-2.08 *$ & 0.91 & $2.82 *$ \\
\hline TRINITY_DN19315_c2_g1_i2 & E3 ubiquitin-protein ligase RMA1H1 & $2.94 *$ & 1.84 & -0.75 & 0.89 \\
\hline TRINITY_DN17399_c2_g1_i1 & NDR1/HIN1-like protein 2 & 4.54 & $-3.19 *$ & -0.57 & -1.05 \\
\hline TRINITY_DN16733_c1_g1_i7 & Annexin D4 & $2.72 *$ & $-5.55^{*}$ & -1.32 & 1.74 \\
\hline TRINITY_DN15770_c0_g1_i7 & $\begin{array}{c}\text { Mitogen-activated protein } \\
\text { kinase } 3\end{array}$ & $2.12 *$ & $-1.74 *$ & -0.54 & -0.35 \\
\hline TRINITY_DN16314_c0_g3_i2 & $\begin{array}{l}\text { NAC domain-containing } \\
\text { protein } 2\end{array}$ & $2.30 *$ & $-2.04 *$ & -0.56 & 1.16 \\
\hline TRINITY_DN22670_c0_g2_i2 & $\begin{array}{l}\text { Leucine-rich repeat receptor-like } \\
\text { serine/threonine-protein kinase }\end{array}$ & 1.67 & $-6.48 *$ & -0.51 & 5.47 \\
\hline TRINITY_DN16553_c1_g3_i1 & $\begin{array}{l}\text { Wall-associated receptor } \\
\text { kinase-like } 20\end{array}$ & $3.20 *$ & 0.86 & $-1.85^{*}$ & -0.05 \\
\hline TRINITY_DN20729_c2_g1_i1 & Protein EDS1 & $2.09 *$ & $-1.58 *$ & $-1.83 *$ & -0.44 \\
\hline TRINITY_DN14123_c3_g1_i2 & Probable receptor-like protein kinase & $1.75 *$ & $1.26 *$ & $-2.12 *$ & -0.72 \\
\hline
\end{tabular}

LogFC values of genes differentially expressed are highlighted with an asterisk*.

We identified DEGs induced only in $S$. arcanum from 0 to $8 \mathrm{hpi}$, such as genes that codify a polyphenol oxidase E (Solyc08g074620.3), an E3 ubiquitin protein-ligase (Solyc12g049330.2), a putative late blight resistance protein (Solyc05g012900.3), and a wallassociated receptor kinase-like (TRINITY_DN16553_c1_g3_i1). The last one also appeared from 8 to 24 hpi but repressed (Table 2). Likewise, induced genes in S. arcanum and repressed in $S$. lycopersicum were detected from 0 to $8 \mathrm{hpi}$, such as a gene that codifies a rust resistance kinase Lr10 (Solyc02g081500.3, which is repressed in S. arcanum from 8 to 24 hpi), a leucine-rich repeat receptor like serine/threonine protein kinase (Solyc11g017270.2), an unannotated gene with function related to serine type endopeptidase inhibitory activity (TRINITY_DN15795_c0_g2_i2), an ankyrin repeat-containing protein (Solyc08g062360.3, later repressed in S. arcanum from 8 to $24 \mathrm{hpi}$ ), an L-type lectin-domain containing receptor kinase (TRINITY_DN22346_c2_g3_i1, later induced in S. lycopersicum from 8 to 24 hpi), a mitogen-activated protein kinase 3 (TRINITY_DN15770_c0_g1_i7), and others (Table 2). Also, induced genes in both tomato species were detected from 0 to $8 \mathrm{hpi}$. However, some of them were strongly expressed in S. arcanum (Table 2), as is the case of a gene that codifies a probable receptor-like serine/threonine protein kinase (Solyc01g109590.3, which is repressed in S. arcanum from 8 to $24 \mathrm{hpi}$ ), and a class V chitinase (Solyc07g005090.3). We have also identified the top ten induced genes in S. arcanum with no transcripts assigned to $S$. $l y-$ copersicum detected with the DA approach (Table 3). Some of these induced genes may have an important role during the first hours of the defense response to $\mathrm{Cmm}$, such as the genes that encode for a bidirectional sugar transporter SWEET2a (TRINITY_DN13677_c0_g1_i8) or the aquaporin PIP2-1 (TRINITY_DN15481_c0_g1_i3). Our study hosts many other genes of interest that can be identified by comparison of the two tomato species and the information provided in Tables S3-S8.

Several QTLs have been previously related to the resistance against Cmm [15-17]. We traced the regions spanning the QTLs in the S. lycopersicum genome, and we found 70 transcripts on chromosome 5, 42 on chromosome 7, and 2479 on chromosome 9 (Table S10). Interestingly, some of these transcripts were highly expressed in $S$. arcanum only at the first few hours of infection (Table 4). However, that is not the case in S. lycopersicum, where transcripts seemed to have little induction, or even downregulation. Moreover, the annotation of these transcripts correlates with previously published proteins involved in disease immunity. 
Table 3. Top ten genes induced in S. arcanum with no transcripts assigned to S. lycopersicum after DA approach.

\begin{tabular}{|c|c|c|}
\hline Gene/Transcript ID & Description & S. arc LogFC \\
\hline \multicolumn{3}{|c|}{$0-8 \mathrm{hpi}$} \\
\hline TRINITY_DN14010_c2_g1_i5 & Tetraspanin-3 & 4.48 \\
\hline TRINITY_DN24943_c4_g1_i9 & Linoleate 13S-lipoxygenase 2-1 & 3.88 \\
\hline TRINITY_DN18887_c0_g4_i2 & UDP-glycosyltransferase $85 \mathrm{~A} 8$ & 3.80 \\
\hline TRINITY_DN16833_c0_g1_i15 & Unknown & 3.44 \\
\hline TRINITY_DN13677_c0_g1_i8 & Bidirectional sugar transporter SWEET2a & 3.16 \\
\hline TRINITY_DN23205_c0_g6_i3 & Ethylene-responsive transcription factor 1 & 2.95 \\
\hline TRINITY_DN23169_c1_g1_i1 & $\gamma$ aminobutyrate transaminase 2 & 2.78 \\
\hline TRINITY_DN19385_c0_g1_i7 & Heavy metal-associated isoprenylated plant protein 32 & 2.63 \\
\hline TRINITY_DN18065_c0_g1_i1 & Allene oxide synthase 2 chloroplastic & 2.48 \\
\hline TRINITY_DN20602_c0_g1_i4 & Ethylene-responsive transcription factor 5 & 2.45 \\
\hline \multicolumn{3}{|c|}{ 8-24 hpi } \\
\hline TRINITY_DN21371_c0_g1_i15 & Stromal 70 kDa heat shock-related protein & 6.39 \\
\hline TRINITY_DN16003_c0_g1_i7 & Glyceraldehyde-3-phosphate dehydrogenase & 3.67 \\
\hline TRINITY_DN15481_c0_g1_i3 & Aquaporin PIP2-1 & 3.26 \\
\hline TRINITY_DN17153_c0_g1_i7 & Heat shock cognate $70 \mathrm{kDa}$ protein 2 & 3.24 \\
\hline TRINITY_DN23165_c1_g1_i17 & RuBisCO large subunit-binding protein subunit $\alpha$ & 3.15 \\
\hline TRINITY_DN24736_c3_g1_i8 & Protein LNK1 & 2.74 \\
\hline TRINITY_DN17225_c0_g1_i11 & Protein WVD2-like 7 & 2.7 \\
\hline TRINITY_DN23140_c2_g1_i7 & Ferric reduction oxidase 6 & 2.65 \\
\hline TRINITY_DN25011_c3_g1_i11 & Heat shock $70 \mathrm{kDa}$ protein 15 & 2.52 \\
\hline TRINITY_DN25230_c3_g1_i22 & Serine/arginine-rich splicing factor SC35 & 2.45 \\
\hline
\end{tabular}

Table 4. Transcripts showing upregulation in S. arcanum located at the regions spanning QTLs associated with resistance.

\begin{tabular}{|c|c|c|c|c|c|c|}
\hline \multirow{2}{*}{$\begin{array}{l}\text { Chromosome of QTL } \\
\text { Spanning Region }\end{array}$} & \multirow{2}{*}{ Annotation } & \multirow{2}{*}{ Transcript ID } & \multicolumn{2}{|c|}{ S. $\operatorname{arc} \log F C$} & \multicolumn{2}{|c|}{ S. $\operatorname{lyc} \operatorname{LogFC}$} \\
\hline & & & $0-8$ hpi & $8-24$ hpi & $0-8$ hpi & $8-24$ hpi \\
\hline Ch5 & $\begin{array}{c}\text { UPF0481 } \\
\text { protein At3g47200 }\end{array}$ & TRINITY_DN21279_c1_g1_i2 & 6.90 & -1.33 & 0.35 & -1.33 \\
\hline Ch5 & $\begin{array}{l}\text { Hyoscyamine } \\
\text { 6-dioxygenase }\end{array}$ & TRINITY_DN19945_c3_g1_i7 & 4.37 & 0.64 & 0.65 & 0.64 \\
\hline $\mathrm{Ch} 7$ & Diacylglycerol kinase 7 & TRINITY_DN20884_c0_g1_i10 & 5.82 & 0.26 & 0.45 & -0.34 \\
\hline $\mathrm{Ch} 7$ & $\begin{array}{c}\text { Putative disease } \\
\text { resistance RPP13-like protein } 1\end{array}$ & TRINITY_DN22407_c0_g2_i3 & 1.69 & -1.12 & 0.21 & -0.30 \\
\hline Ch9 & TOM1-like protein 6 & TRINITY_DN22806_c1_g1_i2 & 10.52 & -0.07 & -0.74 & 0.45 \\
\hline
\end{tabular}

\subsection{RNA-Seq Validation Using DEGs Potentially Related to Resistance}

In order to validate the expression profiles of differentially expressed genes identified by the three bioinformatics analyses, we selected five genes potentially related to resistance against Cmm. We carried out a qRT-PCR analysis of samples obtained from independent infection assays in S. lycopersicum and S. arcanum plants (different infected plants from those used in the RNA-Seq experiment). We considered only the infection times of 0 hpi and $8 \mathrm{hpi}$, since our results suggested that the most notable expression changes occurred in this interval of time after infection.

In our RNA-Seq analysis, four genes were detected as induced in S. arcanum. These genes were polyphenol oxidase E (PPO E; Solyc08g074620.3), leucine-rich repeat receptorlike serine-threonine-protein kinase (LRR; Solyc11g017270.2), the orthologous gene ankyrin repeat-containing protein (ANK; Solyc08g062360.3.1), and a protein PHLOEM PROTEIN 2-LIKE A10 (PHLOEM PL2; Solyc02g092140.1), and the expression patterns were alike with the qRT-PCR validation (Figure 6). The fifth gene selected is involved in plant immunity: an MACPF domain-containing protein CAD1 (MACPF; Solyc10g085710.2). According to our RNA-Seq results, this gene was not differentially expressed in S. lycopersicum nor in S. arcanum, and the expression levels were similar to those shown in the qRT-PCR analisys (Figure 6). Overall, the qRT-PCR results agreed with the comparative transcriptome analysis. The primers employed for qRT-PCR validation are shown in Table S9. 
PPO

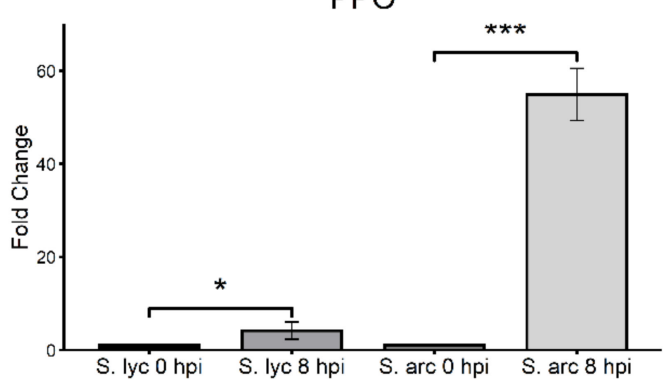

LRR

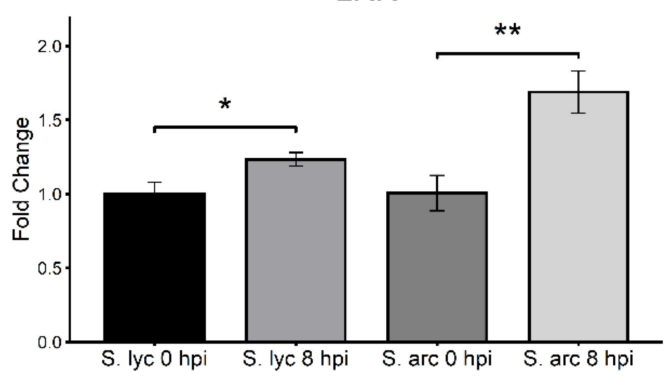

MACPF

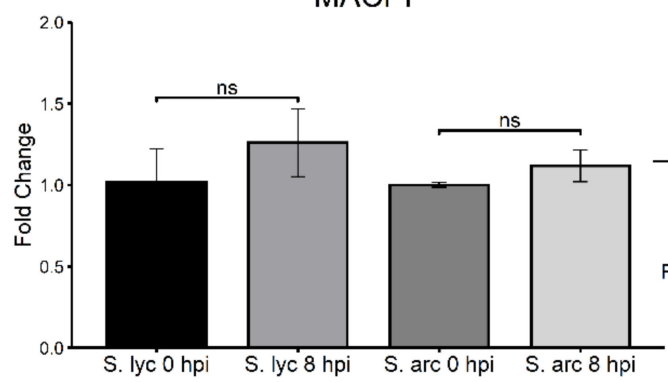

ANK

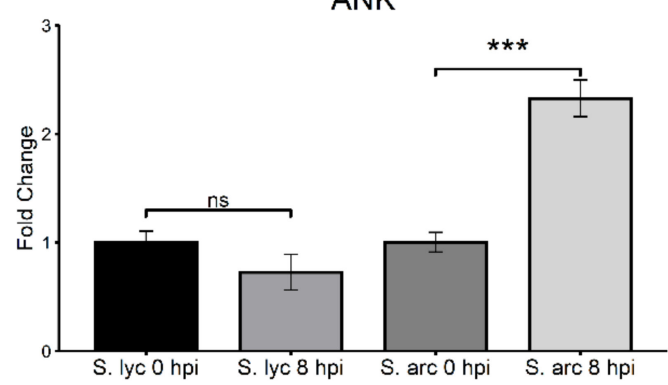

PHLOEM PL2

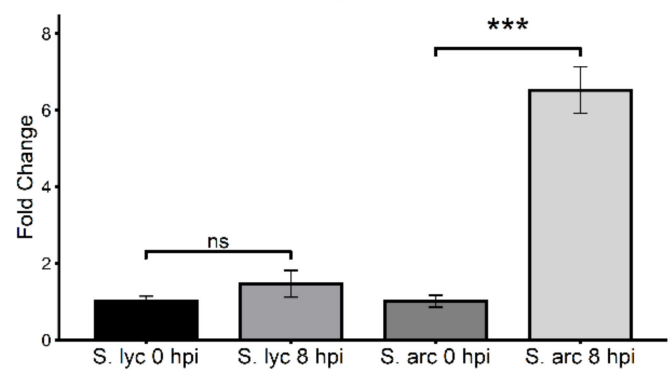

Figure 6. qRT-PCR analysis of selected DEGs. Genes analyzed: polyphenol oxidase E (PPO E; Solyc08g074620.3), leucine-rich repeat receptor-like serine-threonine-protein kinase (LRR; Solyc11g017270.2), ankyrin repeat-containing protein (ANK; Solyc08g062360.3.1), protein PHLOEM PROTEIN 2-LIKE A10 (PHLOEM PL2; Solyc02g092140.1), and MACPF domain-containing protein CAD1 (MACPF; Solyc10g085710.2). The expression levels were normalized to the actin expression (ACTIN1). Data represent fold change of gene expression 0 versus $8 \mathrm{hpi}$. The table compares the fold change values of RNA-Seq analysis versus fold change values from the qRT-PCR validation. The statistically significant differential gene expression between $0 \mathrm{hpi}$ and $8 \mathrm{hpi}$ was assayed by Student's $t$ test; unpaired. ns: $>0.05 .{ }^{*}: p \leq 0.05 .{ }^{* *}: p \leq 0.01$. $^{* * *}: p \leq 0.001$.

\section{Discussion}

We gained further insights about potentially resistance-related genes against $\mathrm{Cmm}$ as a result of the comparison of transcriptional changes in the resistant wild tomato species S. arcanum LA2157 and the susceptible species S. lycopersicum cv. Ailsa Craig. Additionally, mapping of the RNA-Seq raw data of S. arcanum species to the S. lycopersicum reference genome is a reliable strategy, despite the wild tomato species lacking a reference. Therefore, it is possible to use this MR approach for RNA-Seq analyses of wild-type tomato species. Nevertheless, the combination of our three bioinformatics pipelines (MR, STA, and DA) allowed us to obtain additional and complementary gene expression results.

\subsection{From Mapping to a Reference Genome, to a De Novo Assembly Transcriptome; a Complementary Approach}

Transcriptomic studies in non-widely-studied plants are a challenge as there is not enough data available. That is the case of the $S$. arcanum wild tomato species, where, at 
the time this research was conducted, there was not a good enough genome assembly sequence available for mapping. Usually, in an RNA-Seq analysis where there is no reference genome, the first alternative is to perform a de novo transcriptome assembly employing the preferred transcriptome assembling tool, such as Trinity, Oases, or SOAPdenovo-Trans [24-26]. However, the reference genome sequence of $S$. lycopersicum, which is relatively close to S. arcanum [27], has been available since 2012 [28]. Considering this phylogenetic relatedness, we decided to use the S. lycopersicum SL.3.0 reference genome for mapping the obtained reads of both tomato species (MR approach). Since this approach could deliver incomplete results, we decided to complement it and perform two other approaches, referred to as STA and DA (Figure 2).

A feature to highlight in an RNA-Seq analysis is the required computing time. As it has been reported, depending on the number of reads, a de novo transcriptome assembly with Trinity requires long running time periods and a high computing capacity [26], which could be disadvantageous when the latter is limited. According to our analysis, this approach consumed $\sim 279 \mathrm{~h}$ compared with the MR approach, which only consumed $\sim 2 \mathrm{~h}$ of computing time (Table S1). As our data demonstrate, the analysis based on the semi de novo assembly approach is a good alternative for bioinformatics transcriptome analysis, as it required an intermediate computing time of $\sim 25 \mathrm{~h}$ (Table S1). Additionally, it was able to produce a higher number of transcripts in comparison to the other two strategies (Table S2).

Regarding the MR approach, average mapping percentages of S. arcanum LA2157 libraries fluctuated from around 70 to $80 \%$, about $15 \%$ less than the average mapping percentage obtained in S. lycopersicum, which is a small difference given that they are different species. Furthermore, the amount of reads of both tomato species that correctly mapped to the reference genome varied from 70 to $90 \%$, indicating good mapping proportions, which is in accordance with Sangiovanni et al. [29]. Therefore, considering the quality of the reference genome SL3.0, our results indicate a proper mapping for S. arcanum LA2157. Compared to MR, the STA approach improved the average mapping in the wild tomato species (Figure 3c). A similar pattern is present when reads were mapped to the de novo-assembled transcriptome (DA), with a higher mapping percentage of $S$. arcanum with respect to the STA (Figure 3e). Because of the good performance obtained with the Trinity assembler [30,31], we were able to discover new specific features that are not shared between these two related tomato species, or that were not available in the reference genome. These features can be found in the non-annotated genes that were only assigned to GO terms functions (Tables S3-S8), which could be analyzed in future research. Overall, we suggest that some missing information that cannot be obtained by the MR strategy could be compensated for by complementing the results with the DA and STA approaches.

The PCA led us to determine that samples cluster by species and by study condition in all approaches (Figure 3). Additionally, the PCA indicates a cyclic pattern of the biological replicates, since it is possible to observe an overlap between the 0 hpi samples and $24 \mathrm{hpi}$ samples of S. arcanum, not observed in S. lycopersicum (Figure 3). The above results suggest a faster global response of $S$. arcanum to the $\mathrm{Cmm}$ infection in comparison to S. lycopersicum, which could have a delayed response, as has been previously proposed by Lara-Ávila et al. [20].

The total number of DEGs were similar regardless of the used approach. The STA strategy showed more DEGs than the DA strategy (Table 1), and this can be explained because the STA transcriptome is larger (harbors information of annotated genes from the reference genome SL3.0 and additional transcripts obtained after the assembly of unmapped reads; Table S2). Interestingly, in all approaches, we detected an approximately equal proportion of induced genes in both tomato species from 0 to $8 \mathrm{hpi}$ (Table 1). Also, the proportion of repressed genes in S. lycopersicum compared to S. arcanum from 0 to $8 \mathrm{hpi}$ was higher in all the three approaches (Table 1), which can be associated with the cyclic behavior observed in the PCA, and the suggested delayed response (Figure 3). Moreover, after contrasting DEGs of S. lycopersicum and S. arcanum, gene groups are comparable in the three approaches-these groups are shared between species, whereas other genes are 
induced or repressed in only one species (Figure 4). This information is useful to select those that are upregulated in the $S$. arcanum species only, and perhaps play an important role in bacterial plant defense. Overall, these analyses indicate that the number of DEGs detected in each approach is in concordance, and variations between one another are directly related to the number of genes/transcripts in the reference genome or assembled transcriptomes.

\subsection{Global Transcriptional Profiling and Evidence of Resistance-Related Genes}

According to GO term enrichment analysis, numerous functional groups revealed comparable patterns among MR, STA, and DA approaches in S. arcanum and S. lycopersicum (Figures S2-S4), suggesting that both tomato species share similarities in a global transcriptional context. Some of these enriched functions are directly related to plant defense (Figure 5). For example, compared with the resistant species S. arcanum, the general defense response functional group exhibited a higher enrichment level in the susceptible species $S$. lycopersicum from 0 to $8 \mathrm{hpi}$. This result agrees with previous evidence which demonstrated that even when $S$. lycopersicum is generating a defense response after sensing $\mathrm{Cmm}$, it is not effective for counteracting the pathogen infection $[19,32]$.

Importantly, during the transition from 8 to $24 \mathrm{hpi}$, the defense response group enrichment turned from induced genes to repressed genes in S. lycopersicum, whereas in S. arcanum, this functional group was enriched mainly by induced genes at 24 hpi (Figure 5). These findings are in accordance with a recent comparative transcriptome analysis between two different Solanum species and C $\mathrm{mm}$ interaction, where the defense response functional group was not found in the susceptible tomato species S. lycopersicum var. filinta, although this experiment was done at four and eight days after $\mathrm{Cmm}$ inoculation (dai). In contrast, this functional group was enriched at 4 dai in the resistant tomato line S. peruvianum LA2157 [33]. Moreover, the functional groups of defense response specific to bacteria, as well as the defense response to fungi, were mainly enriched by induced genes from 0 to 8 hpi in S. arcanum (Figure 5), suggesting that S. arcanum is triggering a stronger defense response in comparison to $S$. lycopersicum after the challenge.

In addition, Basim et al. [33] reported a gene codifying for a TMV resistance protein $\mathrm{N}$ induced in S. peruvianum LA2157 at 4 dai. Interestingly, it seems that this gene is also participating during the first hours of the defense response to $\mathrm{Cmm}$, as we also found transcripts from TMV resistance protein $\mathrm{N}$ genes mainly induced in $S$. arcanum from 0 to 8 hpi (Tables S3-S8). However, in our study, we did not find the Sn-2 gene that has been associated with a defensive role against $C \mathrm{~mm}$ [34], probably because these genes may have a relevant defensive role several days after the interaction of resistant wild tomato species with Cmm, as has been recently showed in S. peruvianum LA2157 [33].

Although the results obtained by all strategies generally agreed, several functional groups showed enrichment in S. arcanum only in the STA and DA approaches. For example, in the MR approach, the oxylipin biosynthetic process was enriched only in S. lycopersicum from 0 to 8 hpi (Figure 5). However, in the same transition time, this functional group was enriched in $S$. arcanum together with $S$. lycopersicum when we applied the STA and DA approaches. In contrast, the response to wounding GO term was enriched from 0 to 8 hpi in $S$. arcanum in all approaches, but it also appeared enriched in S. lycopersicum from 8 to $24 \mathrm{~h}$ in the DA approach only (Figure 5). The enrichment of this group can be associated with the mechanical damage caused during $\mathrm{Cmm}$ inoculation.

According to our GO terms analysis, several functional groups that have been directly or indirectly associated with defense responses were enriched by induced and repressed genes. The oxylipin biosynthetic process GO term is defined as the chemical reactions and pathways resulting in the formation of oxylipins. Based on previous works that have shown the involvement of oxylipins in plant-pathogen interactions and wounding [35,36], the high enrichment of this group in our analysis may be due to the infection with Cmm, as well as the wounding caused during inoculation. In Arabidopsis thaliana leaves, oxylipins tend to accumulate to high levels during hypersensitive response to Pseudomonas syringae pv. tomato (Pst) expressing the avirulence gene avRpm1 [37]. Correspondingly, silencing of an 
$\alpha$-dioxygenase gene, which is involved in oxylipin biosynthesis, enhances the susceptibility to several bacterial pathogens, and suppresses the hypersensitive response in Capsicum annum [38]. The cytokinin GO term was similarly enriched in both tomato species, particularly with induced genes from 8 to 24 hpi (Figure 5). Cytokinins (Ck) are plant growth hormones that affect plant immunity to several pathogens, such as Rhodococcus fascians. This pathogen produces $\mathrm{Ck}$ recognized by A. thaliana AHK3 and AHK4 receptors, leading to the development of disease symptoms [39]. Nonetheless, it has also been described that endogenous $\mathrm{Ck}$ promotes resistance in A. thaliana in response to Pst, which does not secrete $\mathrm{Ck}$ into the host [40]. It is likely that $\mathrm{Cmm}$ does not secrete $\mathrm{Ck}$ into tomato plants, suggesting that endogenous $\mathrm{Ck}$ are having a protective effect in the wild tomato. Other $\mathrm{GO}$ terms are enriched mainly in S. arcanum, such as mRNA splicing, protein ubiquitination, transmembrane receptor serine/threonine kinase, response to oxidative stress, ubiquitin ligase binding, etc. (Figure 5). These GO terms harbor traits that play several roles in the plant defense response [41-44]. Altogether, these results show some of the genes that may be involved in the defense response background of wild tomato species against $\mathrm{Cmm}$.

Several genes are mainly induced in S. arcanum from 0 to 8 hpi in the MR approach, such as a gene that codifies to a PPO E. Polyphenol oxidases are involved in the oxidation of phenols to quinones. Previous studies have demonstrated a defensive role in transgenic tomato plants overexpressing a PPO of potatoes (Solanum tuberosum). Such transgenic plants exhibited an increased resistance to the pathogen Pst, reducing the bacterial growth, as well as severity of disease symptoms [45]. Moreover, downregulation of the PPO family in tomato, through the introduction of a chimeric antisense potato PPO cDNA, induced an increased susceptibility to $P s t$, suggesting that PPOs have a significant role in limiting disease development [46]. In the STA approach, we identified a non-annotated gene putatively related with serine-type endopeptidase inhibitory activity induced in S. arcanum from 0 to $8 \mathrm{hpi}$. Proteinase inhibitors are characterized as enzymes involved in several biological processes, including plant defense. Proteinase inhibitor StPI from a variety of S. tuberosum resistant to Ralstonia solanacearum is strongly induced during the first 6 to $12 \mathrm{~h}$ after the exposure with the pathogen and jasmonic acid treatment [47]. Likewise, transgenic tobacco lines over-expressing the multi-domain proteinase inhibitor NA-PI from Nicotiana alata and a $\beta$-hordothionin from barley are resistant to the fungal pathogen Botritys cinerea and the bacterial pathogen Pseudomonas solanacearum [48]. Therefore, the fact that we observed induced genes, particularly in S. arcanum, associated with PPOs and putative proteinase inhibitors during the challenge with $\mathrm{Cmm}$, might indicate their relevance in this plant-pathogen interaction.

Our analysis showed DEGs encoding leucine-rich repeat receptor-like kinases (LRRRLKs) in S. arcanum and S. lycopersicum species from 0 to 8 hpi (Table 2 and Tables S2-S8). This was an expected result, since several LRR-RLKs having a role in the defense response have previously been identified. For example, the NILR1 receptor is involved in resistance to parasitic nematodes [49]. In rice (Oryza sativa), the Xa26 gene confers resistance against the bacterial pathogen Xanthomonas oryzae pv. oryzae (Xoo) [50]. Similarly, the overexpression of the ERECTA gene in $A$. thaliana var Ler displays an increased disease resistance to $R$. solanacearum, as indicated by reduced wilt symptoms and impaired bacterial growth [51]. In our study, the observed induction of this group of genes in both tomato species might indicate a role in the defense response against $\mathrm{Cmm}$, and some specific members, such as LRR receptor-like serine/threonine-protein kinase gene products (e.g., Solyc11g017270.2 and TRINITY_DN14123_c3_g1_i2), could be particularly involved.

This study showed the induction of genes encoding proteins related to ankyrin repeatcontaining domain, mostly in $S$. arcanum from 0 to $8 \mathrm{hpi}$. In plants, the ankyrin proteins belong to a large family of proteins involved in diverse functions, including plant defense. In $A$. thaliana, the ankyrin-repeat transmembrane protein BDA1 plays an important role in defense against bacteria. Loss of function mutations in the BDA1 gene result in enhanced disease susceptibility to pathogen Pst DC3000, as well as in the nonpathogenic strain Pst DC30 $h r c C$, whereas a gain-of-function allele of bda1 constitutively activated cell death 
and defense response [52]. Similarly, the XA21 binding protein 25 (XB25), a plant-specific ankyrin-repeat protein of rice, interacts with XA21, a protein that confers resistance to a broad spectrum of Xoo. In addition, the accumulation of XB25 is induced by Xoo infection. The repression of $X b 25$ diminishes the accumulation of $X A 21$, resulting in a compromised disease resistance, indicating that XB25 is required for maintaining XA21-mediated disease resistance [53]. ANK (Solyc08g062360.3.1) was one of the transcripts differentially expressed from 0 to $8 \mathrm{hpi}$ in $S$. arcanum, suggesting that this gene could also be participating during the first hours of the defense response to $\mathrm{Cmm}$.

Another interesting gene detected was a PHLOEM PROTEIN 2-LIKE A10 (PHLOEM PL2; Solyc02g092140.1) gene. Cmm destroys xylem vessels and phloem tissues as the bacteria multiply [10]. Induction of phloem proteins has been associated with diverse external stresses, including pathogenic attack. In our experiment, PHLOEM PROTEIN 2-LIKE A10 was induced in S. arcanum from 0 to 8 hpi (Figure 6), suggesting a protective role against $\mathrm{Cmm}$ infection.

We found several genes that were induced only in S. arcanum (Table 3). For instance, an aquaporin PIP2-1 upregulated at 8-24 h, a class of small, membrane channel proteins that can facilitate selective flux of various small molecules involved in numerous essential processes across membranes. Recently, evidence has pointed to aquaporins having a role in plant defense against pathogens [54]. After pathogen infection, apoplastic $\mathrm{H}_{2} \mathrm{O}_{2}$ is rapidly translocated into the cytoplasm across the plasma membrane (PM). A recent work demonstrated that AtPIP1;4, which is one of the PIP family members in Arabidopsis, is involved in the transport of $\mathrm{H}_{2} \mathrm{O}_{2}$ across the PM [55]. We also found a glyceraldehyde-3-phosphate dehydrogenase (GAPDH), which has been reported to have a role in immune responses to Xanthomonas axonopodis pv. manihotis in cassava [56], and a northern blot analysis showed the accumulation of cytosolic GAPDH gene transcripts in the leaves and stems of inoculated potato plants with an elicitor from the late blight fungal agent Phytophthora infestans [57]. In our analysis, a SWEET2 gene induced in S. arcanum from 0 to 8 hpi. SWEET proteins possess an important role during plant-pathogen interactions. For example, in the roots of Arabidopsis, the loss-of-function SWEET2 mutants are more susceptible to infection by the oomycete Pythium irregulare in comparison to Arabidopsis plants expressing SWEET2, suggesting that SWEET2 activity contributes to resistance to P. irregulare possibly by reducing the availability of glucose in the rhizosphere [58]. Another interesting transcript is one annotated as LNK1. It has been suggested that biotic stress responses are regulated by the circadian clock in plants, and that bacterial infection disrupts clock gene expression to attenuate immune responses. Recent research has demonstrated that infection with Pseudomonas syringae in wild-type (WT) plants downregulated the expression of several core clock genes $1 \mathrm{~h}$ post-infection, including all members of the night light-inducible and clock-regulated (LNK) gene family, and this effect was attenuated in eds4 mutant, which is a highly susceptible mutant. Furthermore, lnk mutants were more susceptible than the WT to P. syringae infection [59]. Another protein found only in S. arcanum was a $\gamma$ aminobutyrate (GABA) transaminase 2. It has been described that the recognition of bacterial and fungal pathogens has proven to trigger GABA accumulation in several plant species, including tomatoes [60]. The accumulated GABA has been suggested to be transported to the mitochondria, where it undergoes deamination via GABA transaminase (GABAT) to be converted into succinic semialdehyde (SSA) [61].

For many years, geneticists have attempted to clone the resistance genes present in the various QTLs identified for C. michiganensis resistance in S. arcanum. Although some progress has been made, the regions spanning the QTLs are large, and, to our knowledge, a fine mapping has not been published yet. We have analyzed the presence of transcripts in the regions spanning some QTLs. We found 70 transcripts on chromosome 5, 42 on chromosome 7, and 2479 on chromosome 9 (Table S10). Interestingly, the most highly expressed transcript at 0-8 h (TRINITY_DN21279_c1_g1_i2) that has homology to the region spanning the QTL in chromosome 5 (Table 4), has the same annotation as (UPF0481 protein At3g47200) the one recently found on a high-density pepper linkage map, which 
is a possible candidate of a QTL on chromosome 5 also, and it is related to P. capsici resistance [62]. Another interesting transcript is a putative hyoscyamine 6-dioxygenase. These proteins generate free radical species, which is an early event associated with the hypersensitive response (HR). A putative hyoscyamine 6-dioxygenase was also found to be induced at the early stages of infection in a potato cultivar resistant to Phytophthora infestans [63].

On the region of chromosome 7, we found homology to a transcript annotated as a diacylglycerol kinase (DGK) (Table 4). These are very important signaling enzymes that phosphorylate diacylglycerol (DAG) to produce phosphatidic acid (PA). There are two pathways by which PA can be produced: through phospholipase D (PLD); and the coupled phospholipase C (PLC)/DGK route [64]. The PLC/DGK pathway seems to be responsible for the rapid accumulation of PA during exposure to pathogen elicitors from bacteria, fungi, or oomycetes [65]. Moreover, a critical reductive coenzyme (NADPH) is produced by DGK enzymes. An oxidative burst driven by NADPH oxidases takes place in most plant-pathogen interactions, especially in incompatible interactions. DGK enzymatic activity seems to be increased after elicitor treatment in tomato, tobacco, rice, and Arabidopsis plants, as well as upon pathogen infection. It has been suggested that DGK is the principal producer of plant PA, and that it is involved in the basal transcriptome regulation, the stimulation of callose accumulation in the apoplast, and the tolerance to the pathogen Pseudomonas syringae [66]. Moreover, the overexpression of the rice DGK gene (OsBIDK1) in tobacco improved its tolerance to tobacco mosaic virus (TMV) and Phytophthora parasitica var. nicotianae infections [67]. On chromosome 7, we also found an RPP13-like protein 1. RPP13 is an Arabidopsis resistance gene that confers resistance to Hyaloperonospora arabidopsidis [68], and RPP13-like proteins have been found in many other plants associated with disease resistance. In the region of chromosome 9, we found a TOM1-like protein differentially regulated. It has been suggested that TOM1-like proteins have a role in the passage of endocytosed ubiquitinated plasma membrane cargo, and act as gatekeepers for the sorting of protein degradation to the vacuole [69]. Silencing of a homologue of TOM1-L2 (TOL) in Nicotiana benthamiana has reduced bacterial growth, thus, it has been proposed that TOL proteins negatively regulate the plant immune response [70].

On the other hand, Coaker et al. [71] analyzed the proteome of a susceptible tomato line and two isogenic tomato lines infected with Cmm and containing the QTLs Rcm 5.1 and Rcm 2 identified in S. habrochaites LA408, which are proteins related to Cmm resistance. This study revealed a role of oxidative stress in response to $\mathrm{Cmm}$, since three distinct superoxide dismutase enzymes (SOD) were differentially regulated among the genotypes analyzed. Interestingly, we also found transcripts from superoxide dismutase genes mainly induced in S. arcanum from 8 to 24 hpi by the three analysis approaches (Tables S3-S8), which supports the previous finding made by Coaker et al. [71].

We validated our RNA-Seq results by qRT-PCR assays of five different genes related to the functions discussed above: a gene encoding a polyphenol oxidase E; an ankyrin repeat-containing protein; a LRR receptor-like serine/threonine-protein kinase; a protein PHLOEM PROTEIN 2-LIKE A10; and a MACPF domain-containing protein CAD1. The qRT-PCR results agree with the gene expression profiles observed in the RNA-Seq (Figure 6), supporting the reproducibility of our results. The moderate variation in gene expression levels is due to the qRT-PCR sensitivity, together with the inherent biological variability resulting from two independent infection assays in two different tomato species (one for RNA-Seq, and one for qRT-PCR). Therefore, these results provide not only statistical significance, but also biological significance to our analyses.

Most importantly, despite showing enriched GO terms related to defense, S. lycopersicum is unable to overcome $\mathrm{Cmm}$ infection. Our results suggest a delayed response in S. lycopersicum compared with the wild S. arcanum. Moreover, S. arcanum seems to have more induced genes at the first few hours after inoculation related to bacterial, oomycete, and fungal defense. Our mapping results also suggest high conservation levels between both species. However, there are some specific genes only upregulated in S. arcanum during 
$\mathrm{Cmm}$ interaction, suggesting that the resistance regulatory mechanism probably diverged during the domestication process. However, we cannot rule out the possibility that those genes specific to S. arcanum, which we could only find in the de novo assembly, have an important contribution in the defense against $\mathrm{Cmm}$.

\section{Conclusions}

Our results demonstrated not only the feasibility of mapping to a closely related species, but also the relevance of a de novo or a semi de novo approach. They also showed consistent results that revealed many interesting genes that contribute to the resistance phenotype. Additionally, a qRT-PCR assay confirmed differential gene expression on some of the candidates. Our functional analysis has unfolded a diversity of processes associated with the differential phenotype. The huge amount of data generated by this study will surely contribute to a deeper understanding of defenses against $\mathrm{Cmm}$. However, further analysis of this defense signaling network, to find genetic variations and, possibly, divergent regulation, would be essential to unleash the resistance processes taking place in both species. Differentially expressed genes between resistant and susceptible varieties, and their functional analysis contribute to the search for new options for generating resistant tomato varieties.

\section{Materials and Methods}

\subsection{Pathogenic Cmm Strain and Plant Material}

S. lycopersicum cv. Ailsa Craig tomato seeds were obtained from the University of Nottingham (Nottingham, UK). S. arcanum LA2157 seeds were acquired from the Tomato Genetics Resource Center (TGRC, Davis, CA, USA). Cmm 1569 strain was isolated from a farming area in Chiapas, Mexico, and donated by Dr. Pablo Lara-Ávila.

\subsection{Growth Conditions and Plant Infection}

All experiments were carried out in controlled conditions, as described below. Before germination, all tomato seeds were sterilized in a 10\% Extran solution for $15 \mathrm{~min}$. Subsequently, three washes with deionized water and one wash with $70 \%$ ethanol solution were performed, followed by a $10 \%$ bleach solution wash for $10 \mathrm{~min}$, and rinsing three times in deionized water. Tomato seeds were germinated in a commercial mix substrate (Sunshine Mix \#3, Sun Grow Horticulture, Vancouver, BC, CA, USA) and a bioclimatic chamber at $25^{\circ} \mathrm{C}$ with a $16 / 8 \mathrm{~h}$ light and dark period. Two weeks later, plants were transferred to greenhouse conditions with a controlled minimum and maximum temperature of $20-28{ }^{\circ} \mathrm{C}$, and a humidity of $55-60 \%$.

Forty days after germination, both tomato species were infected with the pathogenic strain Cmm 1569. The bacterial cells were propagated in an 802-medium culture ( $2 \mathrm{~g} \mathrm{~L}^{-1}$ yeast extract, $1 \mathrm{~g} \mathrm{~L}^{-1}$ polypeptone and $0.92 \mathrm{~g} \mathrm{~L}^{-1}$ magnesium sulfate). For inoculation, three biological replicates per tomato species (S. lycopersicum cv. Ailsa Craig and S. arcanum LA2157) were inoculated in the first proximal internode above ground using an insulin syringe with a $\mathrm{Cmm}$ solution at a concentration of $5 \times 107 \mathrm{CFU}(\mathrm{OD}=0.2)$. Plants were sampled (true leaves next to the inoculation site) at 0,8 , and $24 \mathrm{hpi}$. Samples were immediately frozen in liquid nitrogen, and stored at $-80^{\circ} \mathrm{C}$. The plants were maintained in greenhouse conditions until the appearance of the characteristic disease symptoms.

\subsection{Cdna Library Preparation and RNA-Seq}

The 18 samples (nine samples from each plant species) were sent to the Beijing Genome Institute (BGI. Shenzhen, China). After the total RNA extraction and DNase I treatment, magnetic beads with oligo (dT) are used to isolate mRNA (for eukaryotes), or by removing rRNAs from the total RNA (for prokaryotes). Mixed with the fragmentation buffer, the mRNA is fragmented into short fragments. Then, cDNA is synthesized using the mRNA fragments as templates. Short fragments are purified and resolved with EB buffer for end reparation and single nucleotide A (adenine) addition. After that, the short fragments are 
connected with adapters. The suitable fragments are selected for the PCR amplification as templates. During the QC steps, Agilent 2100 Bioanaylzer, and ABI StepOnePlus Real-Time PCR System are used in quantification and qualification of the sample library. TruSeq paired-end libraries were produced, and sequenced with Illumina Hiseq10X (Illumina, Inc., San Diego, CA, USA). Multiplex sequencing was performed, and the average targeted length obtained per read was $150 \mathrm{bp}$.

\subsection{Map to the S. lycopersicum Genome SL3.0}

This pipeline was designed to quantify gene expression using the S. lycopersicum genome SL3.0 as reference, available at the time this research was conducted (we employed a cluster with 18 FAT nodes and 400 GB in RAM with 32 processors; Table S1). Raw reads quality assessment was performed using the program FastQC (https:/ / www.bioinformatics.babraham. ac.uk/projects / fastqc/, accessed on 20 April 2021). A summary of all FastQC reports was performed with MultiQC [72]. The paired-end reads of each sample were mapped to S. lycopersicum genome version SL3.0 (https:/ / solgenomics.net/organism/Solanum_lycopersicum/, accessed on 20 April 2021) with HISAT version 2.1.0 [73] using default parameters and the non-deterministic option. Mappings were sorted with Samtools version 1.3 [74]. Mapping results summaries were analyzed with an in-house R script (https:/ / github.com/cesaremov / Solanum_Arcanum-Lycopersicum, accessed on 20 April 2021). Fragment quantification assignment to exons per gene identifier was performed with FeatureCounts version 1.6.2 [75]. Quantification results were analyzed and processed with an in-house R script to obtain counts and counts per million (cpm) tables. A principal component analysis was performed using cpm tables as input to prcomp function from the $\mathrm{R}$ stats package using the transcripts per million matrices obtained in each strategy as input (count matrix adjustment by Z-score function) [76]. A counts table was used as input to the differential expression analysis with the R package EdgeR [77]. The counts table was filtered to keep only transcripts with cpm $\geq 4$ in at least nine samples. Dispersion was estimated with the EdgeR function estimateDisp with default parameters. Subsequently, the data was fitted to the negative binomial distribution with the EdgeR function glmQLFit using default parameters. We compared the data of S. arcanum from 0 to $8 \mathrm{hpi}$ with the data of $S$. lycopersicum from the same time transition; and data of $S$. arcanum from 8 to 24 hpi with the data of S. lycopersicum from the same time transition. The EdgeR function glmQLMFTest was used to compare between conditions. Multiple testing correction was performed using the p.adjust function from $\mathrm{R}$ base.

To assess GO term enrichment [78], a logistic classification model defined by the generalized linear model (GLM) was employed. The $g l m$ function was used from the $\mathrm{R}$ stats package. The formula provided to the GLM was index statistics, where the index is a Boolean index indicating if genes belong to a GO term. The statistics were defined by the score $=\operatorname{sign}(\log F C)^{*}-\log 10($ p.value $)$ for each species. Weights in GLM were defined as the ratio of genes not in GO term to genes in GO term. The link function was set to logit. To assess GO term enrichment when both tomato species are competing, we used GLM as previously mentioned, but used both species scores in the same model. The formula for the model with species competing was: index statistic_S._arcanum + statistic_S._lycopersicum. Each statistic is defined, as before, with scores of each species in the same model.

\subsection{Map to the Semi De Novo Transcriptome}

In this pipeline, the paired-end reads not mapped to the genome were assembled. All unmapped paired reads were gathered into one single sequence file. These unmapped reads were assembled using Trinity version 2.6.6 with default parameters to obtain unmapped transcripts [26]. The spliced junction mapped fragments were used to assemble mapped transcripts with StringTie [79] (see first pipeline). Unmapped and mapped assembled transcripts were combined to get a unique semi de novo transcriptomic reference. Coding regions were predicted using Transdecoder (https:/ / github.com/ TransDecoder/TransDecoder/wiki, accessed on 20 April 2021). This semi de novo assembly was functionally annotated using the autoTrinotate.pl program provided by Trinotate 
(https://github.com/Trinotate/Trinotate.github.io/wiki, accessed on 20 April 2021) with the programs BLAST and Hmmer [80]. The databases SwissProt (https:/ / web.expasy.org/ docs / swiss-prot_guideline.html, accessed on 20 April 2021) and Pfam [81] were used for the functional annotation. Each transcript could have one or more of the following functional annotations: blastx; blastp; Pfam; eggnog; or gene ontology. All RNA-Seq paired-end reads for each sample were mapped to this semi de novo transcriptomic reference using Kallisto version 0.42.4 [82]. The mapping results were analyzed as in pipeline one. We used Kallisto pseudo-counts (TPM) as input to differential expression analysis with the EdgeR R package. Subsequently, we used the same steps from the first pipeline to perform differential expression analysis.

\subsection{Map to the De Novo Transcriptome}

All forward and reverse paired-end fastq format files were gathered to get only a pair of forward and reverse fastq files using in-house programs. This pair was used as input for Trinity version 2.6.6 [24] with default parameters, and a minimum transcript length of 500 nucleotides. The result of Trinity was a de novo transcriptome assembly, which was used as reference in this third pipeline. Functional annotation was performed in the same way as in the second pipeline. The paired-end reads were mapped to this de novo transcriptome using Kallisto version 0.42 .4 [82] with default parameters. As in the previous two pipelines, in-house $\mathrm{R}$ programs were applied to analyze mapping results. As mentioned in pipeline two, we got Kallisto quantifications for the de novo (third) pipeline with in-house $\mathrm{R}$ programs. The same steps from the first pipeline were followed to perform differential expression analysis.

5.7. Experimental Approach to Find Transcripts Showing Upregulation in S. arcanum Located at the Regions Spanning QTLs Associated with Resistance

The regions spanning the QTLs in chromosomes 5 (44,803,914-52,431,431), $7(1,319,683-$ $1,554,620)$, and $9(1,753,139-2,313,950)$, published on Sen [83], were used as a database from the S. lycopersicum reference genome SL3.0 to do a blast search against the transcripts obtained from the de novo assembly of $S$. arcanum reads.

\subsection{Gene Expression Validation with qRT-PCR Analysis}

Total RNA from infected plants was used for the synthesis of single-stranded cDNA using SuperScript II Reverse Transcriptase and oligo dT (Invitrogen, Carlsbad, CA, USA). The cDNA samples were amplified with gene-specific primers designed in Primer 3.0 [84]. Possible dimers and heterodimers were predicted with Beacon designer tool (Premier Biosoft International, Palo Alto, CA, USA; http:/ / www.premierbiosoft.com/qOligo/Oligo. jsp?PID=1, accessed on 20 April 2021). Possible amplicon secondary structures were detected with UNAFold tool (IDT Company, Coralville, IA, USA; https:/ /www.idtdna.com/ site/account/login? returnurl=\%2FUNAFold, accessed on 20 April 2021). Quantification was performed on an Applied Biosystems, 7500 fast real-time-PCR system version 2.0 (Applied Biosystems, Foster City, CA, USA). The biological replicates of each condition were pooled together. The qRT-PCR reaction was carried out in 96-well plates, and the thermal cycling was: $94{ }^{\circ} \mathrm{C}, 5 \mathrm{~min} ; 40$ cycles of $94^{\circ} \mathrm{C}, 25 \mathrm{~s} ; 60^{\circ} \mathrm{C}, 30 \mathrm{~s}$. Experiments were carried out using Fast SYBR Green Master Mix (Applied Biosystems, Foster City, CA, USA). Expression levels were normalized to the ACTIN1 housekeeping gene. Fold changes in RNA expression were determined using threshold cycles by the $\Delta \Delta C T$ method [85]. For each experiment, the qRT-PCR was performed in triplicates, and the presented values represent the average and standard deviation. 
Supplementary Materials: The following materials are available online at https:/ /www.mdpi.com/ article/10.3390/genes12111745/s1, Figure S1. MA plots of DEGs per analysis approach. FDR 0.01 for MR analysis; FDR 0.1 for STA and DA analysis approaches. (a) Differentially expressed genes dispersion from 0 to 8 hpi. (b) Differentially expressed genes dispersion from 8 to $24 \mathrm{hpi}$. Red dots: repressed genes. Blue dots: induced genes. $x$-axis $=$ mean average abundance $(\log 2$ $\mathrm{CPM}$, counts per million); y-axis = $\log$ ratio ( $\log 2 \mathrm{FC}$ ). Figure S2. GO terms enrichment resulting from MR analysis. (a) Enriched functional groups in biological process ontology (BP). (b) Enriched functional groups in cellular component ontology (CC). (c) Enriched functional groups in molecular function ontology (MF). GO term enrichment was performed using a logistic regression comparing scores of the genes/transcripts. Scores were calculated from LogFC and the $-\log 10$ of FDR values. Figure S3. GO terms enrichment resulting from STA analysis. (a) Enriched functional groups in biological process ontology (BP). (b) Enriched functional groups in cellular component ontology (CC). (c) Enriched functional groups in molecular function ontology (MF). GO term enrichment was performed using a logistic regression comparing scores of the genes/transcripts. Scores were calculated from LogFC and the $-\log 10$ of FDR values. Figure S4. GO terms enrichment resulting from DA analysis. (a) Enriched functional groups in biological process ontology (BP). (b) Enriched functional groups in cellular component ontology (CC). (c) Enriched functional groups in molecular function ontology (MF). GO term enrichment was performed using a logistic regression comparing scores of the genes/transcripts. Scores were calculated from $\operatorname{LogFC}$ and the $-\log 10$ of FDR values. Table S1. Average computing time consumed per strategy. Table S2. Main features of generated transcriptomes. Table S3. MR approach 0-8 hpi. Table S4. MR approach 8-24 hpi. Table S5. STA approach 0-8 hpi. Table S6. STA approach 8-24 hpi. Table S7. DA approach 0-8 hpi. Table S8. DA approach 8-24 hpi. Table S9. List of primers employed for qRT-PCR validation. Table S10. Predicted transcripts spanning QTL regions on S. lycopersicum genome.

Author Contributions: Conceptualization, L.I.P.-B., A.R.-C., and Á.G.A.-S.; methodology, L.I.P.-B., C.O.-V., A.R.-C., and Á.G.A.-S.; validation, L.I.P.-B.; formal analysis, L.I.P.-B. and C.O.-V.; investigation, L.I.P.-B. and C.O.-V.; data curation, L.I.P.-B. and C.O.-V.; writing-original draft preparation, L.I.P.-B. and C.O.-V.; writing-review and editing, L.I.P.-B., C.O.-V., A.R.-C., and Á.G.A.-S.; supervision, A.R.-C. and Á.G.A.-S.; project administration, Á.G.A.-S.; funding acquisition, Á.G.A.-S. and A.R.-C. All authors have read and agreed to the published version of the manuscript.

Funding: This research was funded by CONACYT (Grant No. FMSLP-2013-C01-209337 and 316201) and by the fellowship No. 330869 granted to LIPB and IPICYT financial support. Also, this work was supported by UNAM-DGAPA-PAPIME PE200618 and UNAM-PAPIIT IN220218.

Institutional Review Board Statement: Not applicable.

Informed Consent Statement: Not applicable.

Data Availability Statement: Raw and processed data are available from the Gene Expression Omnibus (GEO), National Center for Biotechnology Information (NCBI) under the accession GSE152330.

Acknowledgments: We would like to thank Carolina Granados-Mendoza and Cintia Gómez-Muñoz for their critical reading of the manuscript. The authors acknowledge the IPICYT Supercomputing National Center's (CNS) computing resources (Thubat Kaal 2.0) provided to process the data, under the project TKII-R2018-COV1. We also thank the National Laboratory LANBAMA-IPICYT and technicians for the clones sequencing and RT-qPCR analyses.

Conflicts of Interest: The authors declare no conflict of interest.

\section{References}

1. Smith, E.F. A new tomato disease of economic importance. Science 1910, 31, 794-796.

2. CABI. Clavibacter michiganensis subsp. michiganensis. In Invasive Species Compendium; CAB International: Wallingford, UK, 2021; Available online: www.cabi.org/isc (accessed on 1 September 2021).

3. Mansfield, J.; Genin, S.; Magori, S.; Citovsky, V.; Sriariyanum, M.; Ronald, P.; Dow, M.; Verdier, V.; Beer, S.V.; Machado, M.A.; et al. Top 10 plant pathogenic bacteria in molecular plant pathology. Mol. Plant Pathol. 2012, 13, 614-629. [CrossRef]

4. Borboa, F.J.; Rueda, P.E.O.; Acedo, F.E.; Ponce, J.F.; Cruz, M.; Juárez, O.G.; Ortega, A.M.G. Detección de Clavibacter michiganensis subespecies michiganensis en el tomate del estado de Sonora, México. Rev. Fitotec. Mex. 2009, 32, 319-326.

5. Carlton, W.M.; Braun, E.J.; Gleason, M.L. Ingress of Clavibacter michiganensis subsp. michiganensis into tomato leaves through hydathodes. Phytopathology 1998, 88, 525-529. [CrossRef] [PubMed] 
6. Kontaxis, D.G. Leaf trichomes as avenues for infection by Corynebacterium michiganense. Phytopathology 1962, 52, $1306-1307$.

7. Strider, D.L. Bacterial canker of tomato caused by Corynebacterium michiganense. A literature review and bibliography. NC Agric. Exp. Stn. Tech. Bull. 1969, 193, 1-110.

8. Gitaitis, R.D.; Beaver, R.W.; Voloudakis, A.E. Detection of Clavibacter michiganensis subsp. michiganensis in symptomless tomato transplants. Plant Dis. 1991, 75, 834-838. [CrossRef]

9. Kleitman, F.; Barash, I.; Burger, A.; Iraki, N.; Falah, Y.; Sessa, G.; Weinthal, D.; Chalupowicz, L.; Gartemann, K.H.; Eichenlaub, R.; et al. Characterization of a Clavibacter michiganensis subsp. michiganensis population in Israel. Eur. J. Plant Pathol. 2008, 121, 463-475. [CrossRef]

10. Gleason, M.L.; Gitaitis, R.D.; Ricker, M.D. Recent progress in understanding and controlling bacterial canker of tomato in eastern North America. Plant Dis. 1993, 77, 1069-1076. [CrossRef]

11. Strider, D.L. Survival studies with the tomato bacterial canker organism. Phytopathology 1967, 57, $1067-1071$.

12. Fatmi, M.; Schaad, N.W. Survival of Clavibacter michiganensis ssp. michiganensis in infected tomato stems under natural field conditions in California, Ohio and Morocco. Plant Pathol. 2002, 51, 149-154. [CrossRef]

13. Hausbeck, M.; Bell, J.; Medina-Mora, C.; Podolsky, R.; Fulbright, D. Effect of bactericides on population sizes and spread of Clavibacter michiganensis subsp. michiganensis on tomatoes in the greenhouse and on disease development and crop yield in the field. Phytopathology 2000, 90, 38-44. [CrossRef]

14. De León, L.; Siverio, F.; López, M.M.; Rodríguez, A. Comparative efficiency of chemical compounds for in vitro and in vivo activity against Clavibacter michiganensis subsp. michiganensis, the causal agent of tomato bacterial canker. Crop Prot. 2008, 27, 1277-1283. [CrossRef]

15. Van Heusden, A.W.; Koornneef, M.; Voorrips, R.E.; Bruggemann, W.; Pet, G.; van Ginkel, R.V.; Chen, X.; Lindhout, P. Three QTLs from Lycopersicon peruvianum confer a high level of resistance to Clavibacter michiganensis ssp. michiganensis. Theor. Appl. Genet. 1999, 99, 1068-1074. [CrossRef]

16. Francis, D.M.; Kabelka, E.; Bell, J.; Franchino, B.; St Clair, D. Resistance to bacterial canker in tomato (Lycopersicon hirsutum LA407) and its progeny derived from crosses to L. esculentum. Plant Dis. 2001, 85, 1171-1176. [CrossRef]

17. Kabelka, E.; Franchino, B.; Francis, D.M. Two loci from Lycopersicon hirsutum LA407 confer resistance to strains of Clavibacter michiganensis subsp. michiganensis. Phytopathology 2002, 92, 504-510. [CrossRef]

18. Sen, Y.; Zhu, F.; Vandenbroucke, H.; van der Wolf, J.; Visser, R.; van Heusden, A.W. Screening for new sources of resistance to Clavibacter michiganensis subsp. michiganensis (Cmm) in tomato. Euphytica 2013, 190, 309-317. [CrossRef]

19. Balaji, V.; Mayrose, M.; Sherf, O.; Jacob-Hirsch, J.; Eichenlaub, R.; Iraki, N.; Manulis-Sasson, S.; Rechavi, G.; Barash, I.; Sessa, G. Tomato transcriptional changes in response to Clavibacter michiganensis subsp. michiganensis reveal a role for ethylene in disease development. Plant Physiol. 2008, 146, 1797-1809. [CrossRef] [PubMed]

20. Lara-Ávila, J.P.; Isordia-Jasso, M.I.; Castillo-Collazo, R.; Simpson, J.; Alpuche-Solís, Á.G. Gene expression analysis during interaction of tomato and related wild species with Clavibacter michiganensis subsp. michiganensis. Plant Mol. Biol. Rep. 2012, 30 , 498-511. [CrossRef]

21. Ameur, A.; Wetterbom, A.; Feuk, L.; Gyllensten, U. Global and unbiased detection of splice junctions from RNA-seq data. Genome Biol. 2010, 11, R34. [CrossRef] [PubMed]

22. Ozsolak, F.; Milos, P. RNA sequencing: Advances, challenges and opportunities. Nat. Rev. Genet. 2011, 12, 87-98. [CrossRef]

23. Slatko, B.E.; Gardner, A.F.; Ausubel, F.M. Overview of next-generation sequencing technologies. Curr. Protoc. Mol. Biol. 2018, 122, e59. [CrossRef]

24. Grabherr, M.G.; Haas, B.J.; Yassour, M.; Levin, J.Z.; Thompson, D.A.; Amit, I.; Adiconis, X.; Fan, L.; Raychowdhury, R.; Zeng, Q.; et al. Full-length transcriptome assembly from RNA-Seq data without a reference genome. Nat. Biotechnol. 2011, $29,644-652$. [CrossRef]

25. Schulz, M.H.; Zerbino, D.R.; Vingron, M.; Birney, E. Oases: Robust de novo RNA-seq assembly across the dynamic range of expression levels. Bioinformatics 2012, 28, 1086-1092. [CrossRef] [PubMed]

26. Xie, Y.; Wu, G.; Tang, J.; Luo, R.; Patterson, J.; Liu, S.; Huang, W.; He, G.; Gu, S.; Li, S.; et al. SOAPdenovo-Trans: De novo transcriptome assembly with short RNA-Seq reads. Bioinformatics 2014, 30, 1660-1666. [CrossRef] [PubMed]

27. Rodriguez, F.; Wu, F.; Ané, C.; Tanksley, S.; Spooner, D.M. Do potatoes and tomatoes have a single evolutionary history, and what proportion of the genome supports this history? BMC Evol. Biol. 2009, 9, 191. [CrossRef]

28. The Tomato Genome Consortium. The tomato genome sequence provides insights into fleshy fruit evolution. Nature 2012, 485, 635-641. [CrossRef] [PubMed]

29. Sangiovanni, M.; Granata, I.; Thind, A.S.; Guarracino, M.R. From trash to treasure: Detecting unexpected contamination in unmapped NGS data. BMC Bioinform. 2019, 20, 168. [CrossRef]

30. Honaas, L.A.; Wafula, E.K.; Wickett, N.J.; Der, J.P.; Zhang, Y.; Edger, P.P.; Altman, N.S.; Pires, J.C.; Leebens-Mack, J.H.; dePamphilis, C.W. Selecting superior de novo transcriptome assemblies: Lessons learned by leveraging the best plant genome. PLoS ONE 2016, 11, e0146062. [CrossRef] [PubMed]

31. Hölzer, M.; Marz, M. De novo transcriptome assembly: A comprehensive cross-species comparison of short-read RNA-Seq assemblers. GigaScience 2019, 8, giz039. [CrossRef] 
32. Savidor, A.; Teper, D.; Gartemann, K.H.; Eichenlaub, R.; Chalupowicz, L.; Manulis-Sasson, S.; Barash, I.; Tews, H.; Mayer, K.; Giannone, R.J.; et al. The Clavibacter michiganensis subsp. michiganensis-Tomato interactome reveals the perception of pathogen by the host and suggests mechanisms of infection. J. Proteome Res. 2012, 11, 736-750. [CrossRef]

33. Basim, H.; Basim, E.; Tombuloglu, H.; Unver, T. Comparative transcriptome analysis of resistant and cultivated tomato lines in response to Clavibacter michiganensis subsp. michiganensis. Genomics 2021, 113, 2455-2467. [CrossRef] [PubMed]

34. Balaji, V.; Smart, C.D. Over-expression of snakin-2 and extensin-like protein genes restricts pathogen invasiveness and enhances tolerance to Clavibacter michiganensis subsp. michiganensis in transgenic tomato (Solanum lycopersicum). Transgenic Res. 2012, 21, 23-37. [CrossRef]

35. Weber, H.; Vick, B.A.; Farmer, E.E. Dinor-oxo-phytodienoic acid: A new hexadecanoid signal in the jasmonate family. Proc. Natl. Acad. Sci. USA 1997, 94, 10473-10478. [CrossRef] [PubMed]

36. Weber, H.; Chételat, A.; Caldelari, D.; Farmer, E.E. Divinyl ether fatty acid synthesis in late blight-diseased potato leaves. Plant Cell 1999, 11, 485-494. [CrossRef] [PubMed]

37. Vollenweider, S.; Weber, H.; Stolz, S.; Chételat, A.; Farmer, E.E. Fatty acid ketodienes and fatty acid ketotrienes: Michael addition acceptors that accumulate in wounded and diseased Arabidopsis leaves. Plant J. 2000, 24, 467-476. [CrossRef] [PubMed]

38. Hong, C.E.; Ha, Y.I.; Choi, H.; Moon, J.Y.; Lee, J.; Shin, A.Y.; Park, C.J.; Yoon, G.M.; Kwon, S.Y.; Jo, I.H.; et al. Silencing of an $\alpha$-dioxygenase gene, Ca-DOX, retards growth and suppresses basal disease resistance responses in Capsicum annum. Plant Mol. Biol. 2017, 93, 497-509. [CrossRef]

39. Pertry, I.; Václavíková, K.; Depuydt, S.; Galuszka, P.; Spíchal, L.; Temmerman, W.; Stes, E.; Schmülling, T.; Kakimoto, T.; van Montagu, M.; et al. Identification of Rhodococcus fascians cytokinins and their modus operandi to reshape the plant. Proc. Natl. Acad. Sci. USA 2009, 106, 929-934. [CrossRef]

40. Choi, J.; Huh, S.U.; Kojima, M.; Sakakibara, H.; Paek, K.; Hwang, I. The cytokinin-activated transcription factor ARR2 promotes plant immunity via TGA3/NPR1-dependent salicylic acid signaling in Arabidopsis. Dev. Cell 2010, 19, 284-295. [CrossRef]

41. Gómez-Gómez, L.; Boller, T. FLS2: An LRR receptor-like kinase involved in the perception of the bacterial elicitor flagellin in Arabidopsis. Mol. Cell 2000, 5, 1003-1011. [CrossRef]

42. Choi, H.W.; Kim, Y.J.; Lee, S.C.; Hong, J.K.; Hwang, B.K. Hydrogen peroxide generation by the pepper extracellular peroxidase CaPO2 activates local and systemic cell death and defense response to bacterial pathogens. Plant Physiol. 2007, 145, 890-904. [CrossRef] [PubMed]

43. Lee, D.H.; Choi, H.W.; Hwang, B.K. The pepper E3 ubiquitin ligase RING1 gene, CaRING1, is required for cell death and the salicylic acid-dependent defense response. Plant Physiol. 2011, 156, 2011-2025. [CrossRef]

44. Zhang, Z.; Liu, Y.; Ding, P.; Li, Y.; Kong, Q.; Zhang, Y. Splicing of receptor-like kinase-encoding SNC4 and CERK1 is regulated by two conserved splicing factors that are required for plant immunity. Mol. Plant 2014, 7, 1766-1775. [CrossRef]

45. Li, L.; Steffens, J.C. Overexpression of polyphenol oxidase in transgenic tomato plants results in enhanced bacterial disease resistance. Planta 2002, 215, 239-247. [CrossRef]

46. Thipyapong, P.; Hunt, M.D.; Steffens, J.C. Antisense downregulation of polyphenol oxidase results in enhanced disease susceptibility. Planta 2004, 220, 105-117. [CrossRef]

47. Li, G.C.; Jin, L.P.; Xie, K.Y.; Li, Y.; Qu, D.Y. Cloning of proteinase inhibitor gene StPI in diploid potato and its expression analysis. Agr. Sci. China 2007, 6, 1315-1321. [CrossRef]

48. Charity, J.A.; Hughes, P.; Anderson, M.A.; Bittisnich, D.J.; Whitecross, M.; Higgins, T.J.V. Pest and disease protection conferred by expression of barley $\beta$-hordothionin and Nicotiana alata proteinase inhibitor genes in transgenic tobacco. Funct. Plant Biol. 2005, 32, 35-44. [CrossRef] [PubMed]

49. Mendy, B.; Wang'ombe, M.W.; Radakovic, Z.S.; Holbein, J.; Ilyas, M.; Chopra, D.; Holton, N.; Zipfel, C.; Grundler, F.M.; Siddique, $\mathrm{S}$. Arabidopsis leucine-rich repeat receptor-like kinase NILR1 is required for induction of innate immunity to parasitic nematodes. PLoS Pathog. 2017, 13, e1006284. [CrossRef] [PubMed]

50. Sun, X.; Cao, Y.; Yang, Z.; Xu, C.; Li, X.; Wang, S.; Zhang, Q. Xa26, a gene conferring resistance to Xanthomonas oryzae pv. oryzae in rice, encodes an LRR receptor kinase-like protein. Plant J. 2004, 37, 517-527. [CrossRef] [PubMed]

51. Godiard, L.; Sauviac, L.; Torii, K.U.; Grenon, O.; Mangin, B.; Grimsley, N.H.; Marco, Y. ERECTA, an LRR receptor-like kinase protein controlling development pleiotropically affects resistance to bacterial wilt. Plant J. 2003, 36, 353-365. [CrossRef]

52. Yang, Y.; Zhang, Y.; Ding, P.; Johnson, K.; Li, X.; Zhang, Y. The ankyrin-repeat transmembrane protein BDA1 functions downstream of the receptor-like protein SNC2 to regulate plant immunity. Plant Physiol. 2012, 159, 1857-1865. [CrossRef] [PubMed]

53. Jiang, Y.; Chen, X.; Ding, X.; Wang, Y.; Chen, Q.; Song, W.Y. The XA21 binding protein XB25 is required for maintaining XA21-mediated disease resistance. Plant J. 2013, 73, 814-823. [CrossRef]

54. Li, G.; Chen, T.; Zhang, Z.; Li, B.; Tian, S. Roles of aquaporins in plant-pathogen interaction. Plants 2020, 9, 1134. [CrossRef]

55. Tian, S.; Wang, X.; Li, P.; Wang, H.; Ji, H.; Xie, J.; Qiu, Q.; Shen, D.; Dong, H. Plant aquaporin AtPIP1; 4 links apoplastic $\mathrm{H}_{2} \mathrm{O}_{2}$ induction to disease immunity pathways. Plant Physiol. 2016, 171, 1635-1650. [CrossRef]

56. Zeng, H.; Xie, Y.; Liu, G.; Lin, D.; He, C.; Shi, H. Molecular identification of GAPDHs in cassava highlights the antagonism of MeGAPCs and MeATG8s in plant disease resistance against cassava bacterial blight. Plant Mol. Biol. 2018, 97, 201-214. [CrossRef] [PubMed] 
57. Laxalt, A.M.; Cassia, R.O.; Sanllorenti, P.M.; Madrid, E.A.; Andreu, A.B.; Daleo, G.R.; Conde, R.D.; Lamattina, L. Accumulation of cytosolic glyceraldehyde-3-phosphate dehydrogenase RNA under biological stress conditions and elicitor treatments in potato. Plant Mol. Biol. 1996, 30, 961-972. [CrossRef] [PubMed]

58. Chen, H.Y.; Huh, J.H.; Yu, Y.C.; Ho, L.H.; Chen, L.Q.; Tholl, D.; Frommer, W.B.; Guo, W.J. The Arabidopsis vacuolar sugar transporter SWEET2 limits carbon sequestration from roots and restricts Pythium infection. Plant J. 2015, 83, 1046-1058. [CrossRef]

59. De Leone, M.J.; Hernando, C.E.; Romanowski, A.; Careno, D.A.; Soverna, A.F.; Sun, H.; Bologna, N.G.; Vázquez, M.; Schneeberger, K.; Yanovsky, M.J. Bacterial infection disrupts clock gene expression to attenuate immune responses. Curr. Biol. 2020, 30, 1740-1747. [CrossRef] [PubMed]

60. Wang, G.; Kong, J.; Cui, D.; Zhao, H.; Niu, Y.; Xu, M.; Jiang, G.; Zhao, Y.; Wang, W. Resistance against Ralstonia solanacearum in tomato depends on the methionine cycle and the $\gamma$-aminobutyric acid metabolic pathway. Plant J. 2019, 97, 1032-1047. [CrossRef]

61. Shelp, B.J.; Zarei, A. Subcellular compartmentation of 4-aminobutyrate (GABA) metabolism in arabidopsis: An update. Plant Signal. Behav. 2017, 12, e1322244. [CrossRef]

62. Li, Y.F.; Zhang, S.C.; Yang, X.M.; Wang, C.P.; Huang, Q.Z.; Huang, R.-Z. Generation of a High-Density Genetic Map of Pepper (Capsicum annuum L.) by SLAF-seq and QTL Analysis of Phytophthora capsici Resistance. Horticulturae 2021, 7, 92. [CrossRef]

63. Birch, P.R.; Avrova, A.O.; Duncan, J.M.; Lyon, G.D.; Toth, R.L. Isolation of potato genes that are induced during an early stage of the hypersensitive response to Phytophthora infestans. Mol. Plant Microbe Interact. 1999, 12, 356-361. [CrossRef]

64. Escobar-Sepúlveda, H.F.; Trejo-Téllez, L.I.; Pérez-Rodríguez, P.; Hidalgo-Contreras, J.V.; Gómez-Merino, F.C. Diacylglycerol kinases are widespread in higher plants and display inducible gene expression in response to beneficial elements, metal, and metalloid ions. Front. Plant Sci. 2017, 8, 129. [CrossRef]

65. Arisz, S.A.; Testerink, C.; Munnik, T. Plant PA signaling via diacylglycerol kinase. Biochim. Biophys. Acta 2009, 1791, 869-875. [CrossRef]

66. Kue Foka, I.C.; Ketehouli, T.; Zhou, Y.; Li, X.W.; Wang, F.W.; Li, H. The emerging roles of diacylglycerol kinase (DGK) in plant stress tolerance, growth, and development. Agronomy 2020, 10, 1375. [CrossRef]

67. Zhang, W.; Chen, J.; Zhang, H.; Song, F. Overexpression of a rice diacylglycerol kinase gene OsBIDK1 enhances disease resistance in transgenic tobacco. Mol. Cells 2008, 26, 258-264.

68. Bittner-Eddy, P.D.; Crute, I.R.; Holub, E.B.; Beynon, J.L. RPP13 is a simple locus in Arabidopsis thaliana for alleles that specify downy mildew resistance to different avirulence determinants in Peronospora parasitica. Plant J. 2000, 21, 177-188. [CrossRef] [PubMed]

69. Roach, T.G.; Lång, H.K.; Xiong, W.; Ryhänen, S.J.; Capelluto, D.G. Protein trafficking or cell signaling: A dilemma for the adaptor protein TOM1. Front. Cell Dev. Biol. 2021, 9, 408. [CrossRef]

70. Conlan, B.; Stoll, T.; Gorman, J.J.; Saur, I.; Rathjen, J.P. Development of a rapid in planta BioID system as a probe for plasma membrane-associated immunity proteins. Front. Plant Sci. 2018, 9, 1882. [CrossRef]

71. Coaker, G.L.; Willard, B.; Kinter, M.; Stockinger, E.J.; Francis, D.M. Proteomic analysis of resistance mediated by Rcm 2.0 and Rcm 5.1, two loci controlling resistance to bacterial canker of tomato. Mol. Plant Microbe Interact. 2004, 17, 1019-1028. [CrossRef]

72. Ewels, P.; Magnusson, M.; Lundin, S.; Käller, M. MultiQC: Summarize analysis results for multiple tools and samples in a single report. Bioinformatics 2016, 32, 3047-3048. [CrossRef] [PubMed]

73. Kim, D.; Langmead, B.; Salzberg, S.L. HISAT: A fast spliced aligner with low memory requirements. Nat. Methods 2015, 12, 357-360. [CrossRef]

74. Li, H.; Handsaker, B.; Wysoker, A.; Fennell, T.; Ruan, J.; Homer, N.; Marth, G.; Abecasis, G.; Durbin, R. 1000 Genome project data processing subgroup. The sequence alignment/map format and SAMtools. Bioinformatics 2009, 25, 2078-2079. [CrossRef]

75. Liao, Y.; Smyth, G.K.; Shi, W. Featurecounts: An efficient general purpose program for assigning sequence reads to genomic features. Bioinformatics 2014, 30, 923-930. [CrossRef]

76. Le, S.; Josse, J.; Husson, F. FactoMineR: An R package for multivariate analysis. J. Stat. Softw. 2008, 25, 1-18. [CrossRef]

77. Robinson, M.D.; Mccarthy, D.J.; Smyth, G.K. EdgeR: A Bioconductor package for differential expression analysis of digital gene expression data. Bioinformatics 2010, 26, 139-140. [CrossRef] [PubMed]

78. Ashburner, M.; Ball, C.A.; Blake, J.A.; Botstein, D.; Butler, H.; Cherry, J.M.; Davis, A.P.; Dolinski, K.; Dwight, S.S.; Eppig, J.T.; et al. Gene ontology: Tool for the unification of biology. The Gene Ontology Consortium. Nat. Genet. 2000, 25, 25-29. [CrossRef]

79. Pertea, M.; Pertea, G.M.; Antonescu, C.M.; Chang, T.C.; Mendell, J.T.; Salzberg, S.L. StringTie enables improved reconstruction of a transcriptome from RNA-seq reads. Nat. Biotechnol. 2015, 33, 290-295. [CrossRef] [PubMed]

80. Finn, R.D.; Clements, J.; Eddy, S.R. HMMER web server: Interactive sequence similarity searching. Nucleic Acids Res. 2011, 39, 29-37. [CrossRef]

81. Punta, M.; Coggill, P.C.; Eberhardt, R.Y.; Mistry, J.; Tate, J.; Boursnell, C.; Pang, N.; Forslund, K.; Ceric, G.; Clements, J.; et al. The Pfam protein families database. Nucleic Acids Res. 2012, 40, D290-D301. [CrossRef]

82. Bray, N.L.; Pimentel, H.; Melsted, P.; Pachter, L. Near-optimal probabilistic RNA-seq quantification. Nat. Biotechnol. 2016, 34, 525-527. [CrossRef] [PubMed]

83. Sen, Y. Bacterial Canker Resistance in Tomato. Ph.D. Thesis, Wageningen University, Wageningen, The Netherlands, 2014. 
84. Untergasser, A.; Nijveen, H.; Rao, X.; Bisseling, T.; Geurts, R.; Leunissen, J.A. Primer3Plus, an enhanced web interface to Primer3. Nucleic Acids Res. 2007, 35, W71-W74. [CrossRef] [PubMed]

85. Livak, K.J.; Schmittgen, T.D. Analysis of relative gene expression data using real-time quantitative PCR and the 2(-Delta Delta C(T)) Method. Methods 2001, 25, 402-408. [CrossRef] [PubMed] 